\title{
A role for proteinase-activated receptor-1 in inflammatory bowel diseases
}

\author{
Nathalie Vergnolle, ${ }^{1}$ Laurie Cellars, ${ }^{1}$ Andrea Mencarelli, ${ }^{2}$ Giovanni Rizzo, ${ }^{2}$ Sunita Swaminathan, ${ }^{3}$ \\ Paul Beck, ${ }^{3}$ Martin Steinhoff, ${ }^{4}$ Patricia Andrade-Gordon, ${ }^{5}$ Nigel W. Bunnett, ${ }^{6}$ \\ Morley D. Hollenberg, ${ }^{1}$ John L. Wallace, ${ }^{1}$ Giuseppe Cirino, ${ }^{7}$ and Stefano Fiorucci ${ }^{2}$
}

\begin{abstract}
1Department of Pharmacology and Therapeutics, University of Calgary, Calgary, Alberta, Canada. ${ }^{2}$ Department of Internal Medicine, University of Perugia, Perugia, Italy. ${ }^{3}$ Department of Medicine, University of Calgary, Calgary, Alberta, Canada. ${ }^{4}$ Department of Dermatology, University of Münster, Münster, Germany. ${ }^{5}$ Drug Discovery, Johnson \& Johnson Pharmaceutical Research and Development, Spring House, Pennsylvania, USA. ${ }^{6}$ Department of Surgery and Physiology, UCSF, San Francisco, USA 7Department of Experimental Pharmacology, University of Naples, Naples, Italy.
\end{abstract}

\begin{abstract}
Proteinase-activated receptor-1 $\left(\mathrm{PAR}_{1}\right)$, a G protein-coupled receptor activated by thrombin, is highly expressed in different cell types of the gastrointestinal tract. The activity of thrombin and of other proteinases is significantly increased in the colon of inflammatory bowel disease (IBD) patients. Since PAR activation $_{1}$ in tissues other than the gut provoked inflammation, we hypothesized that $\mathrm{PAR}_{1}$ activation in the colon is involved in the pathogenesis of IBD. Here, we demonstrate that $\mathrm{PAR}_{1}$ is overexpressed in the colon of IBD patients. In mice, intracolonic administration of $\mathrm{PAR}_{1}$ agonists led to an inflammatory reaction characterized by edema and granulocyte infiltration. This $P_{A} R_{1}$ activation-induced inflammation was dependent on $B$ and $T$ lymphocytes. Moreover, $\mathrm{PAR}_{1}$ activation exacerbated and prolonged inflammation in a mouse model of IBD induced by the intracolonic administration of trinitrobenzene sulfonic acid (TNBS), while PAR $_{1}$ antagonism significantly decreased the mortality and severity of colonic inflammation induced by TNBS and

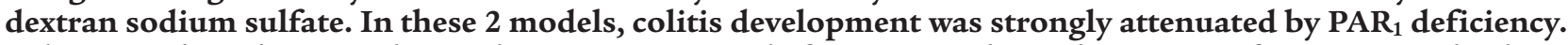
Taken together, these results imply an important role for $\mathrm{PAR}_{1}$ in the pathogenesis of experimental colitis, supporting the notion that $\mathrm{PAR}_{1}$ inhibition may be beneficial in the context of IBD and possibly in other chronic intestinal inflammatory disorders.
\end{abstract}

\section{Introduction}

Proteinase-activated receptors (PARs) are a family of $G$ proteincoupled receptors activated by the proteolytic cleavage of their $\mathrm{N}$-terminal extracellular domain $(1,2)$. The newly exposed aminoterminal domain acts as a tethered ligand, self-activating the receptor. Synthetic peptides corresponding to the receptor-tethered ligand domain can selectively activate PARs, providing useful pharmacological tools to understand the physiology of these receptors (3). a number of endogenous proteinases are able to activate members of the PAR family: thrombin cleaves the N-terminal domain of $\mathrm{PAR}_{1}, \mathrm{PAR}_{3}$, and $\mathrm{PAR}_{4}$, trypsin activates $\mathrm{PAR}_{2}, \mathrm{PAR}_{4}$, and to a lesser extent $\mathrm{PAR}_{1}$, cathepsin $\mathrm{G}$ activates $\mathrm{PAR}_{4}$, and mast cell tryptase can activate $\mathrm{PAR}_{2}$ (4). Like trypsin and thrombin, exogenous proteinases, such as pathogen proteinases, can either activate or disarm PARs, by removing the $\mathrm{N}$-terminal activation site $(4,5)$.

$\mathrm{PAR}_{1}$ was the first member of this family to be cloned and was the first receptor for which this unique mechanism of activation was described (6). The interest in $\mathrm{PAR}_{1}$ was initially driven by research on the receptor responsible for thrombin-induced activation of platelets. However, $\mathrm{PAR}_{1}$ activation mediates several effects of thrombin other than platelet activation, especially inflammation. PAR $_{1}$ activation induces changes in vascular tone, increased vascular permeabil-

Nonstandard abbreviations used: DSS, dextran sodium sulfate; IBD, inflammatory bowel disease; LPMC, lamina propria mononuclear cell; MLCK, myosin light chain kinase; MPO, myeloperoxidase; NK-1, neurokinin-1; PAR, proteinase-activated receptor; TNBS, trinitrobenzene sulfonic acid.

Conflict of interest: The authors have declared that no conflict of interest exists.

Citation for this article: J. Clin. Invest. 114:1444-1456 (2004).

doi:10.1172/JCI200421689. ity, and granulocyte chemotaxis $(4,7)$. In lung epithelial cells, $\mathrm{PAR}_{1}$ agonists stimulate the release of proinflammatory cytokines (IL-6 and IL-8) (8). In vivo, $\mathrm{PAR}_{1}$ agonists can induce inflammation when injected into the paw, the liver, or the brain of rodents (9-12).

In the gut, $\mathrm{PAR}_{1}$ is expressed by a variety of cell types, including enterocytes; endothelial cells; enteric neurons, where it coexpresses with excitatory and inhibitory neurotransmitters (13); terminals of mesenteric afferent nerves; myocytes; and immune cells such as monocytes/macrophages, neutrophils, and lymphocytes $(14,15)$. $\mathrm{PAR}_{1}$ agonists are capable of inducing calciumdependent chloride secretion in rodent and human enterocytes $(14,16,17)$. Moreover, $\mathrm{PAR}_{1}$ agonists are able to increase intestinal permeability both in vivo and in cultured enterocytes, by a mechanism involving the induction of enterocyte apoptosis (17). In the colon, $\mathrm{PAR}_{1}$ agonists also seem to act as growth factors: in human colon cancer cell lines, $\mathrm{PAR}_{1}$ is overexpressed compared with nontransformed cells, and $\mathrm{PAR}_{1}$ activation induces cell proliferation and motility (18). In colonic myofibroblasts, $\mathrm{PAR}_{1}$ agonists increased both COX-2 expression and prostaglandin $\mathrm{E}_{2}$ synthesis, suggesting a mechanism through which $\mathrm{PAR}_{1}$ activation might regulate intestinal functions (19). Intestinal motility also seems to be affected by $\mathrm{PAR}_{1}$ activation. Administration of a $\mathrm{PAR}_{1}$-activating peptide causes a reduction of the spontaneous contractions in intestinal circular muscle preparations and a contractile effect or a biphasic relaxation followed by contraction in a longitudinal muscle preparation of rat intestine $(20,21)$.

The pathogenesis of inflammatory bowel disease (IBD) is believed to be multifactorial, involving genetic and immune factors, as well as environmental factors, and endogenous factors 
A
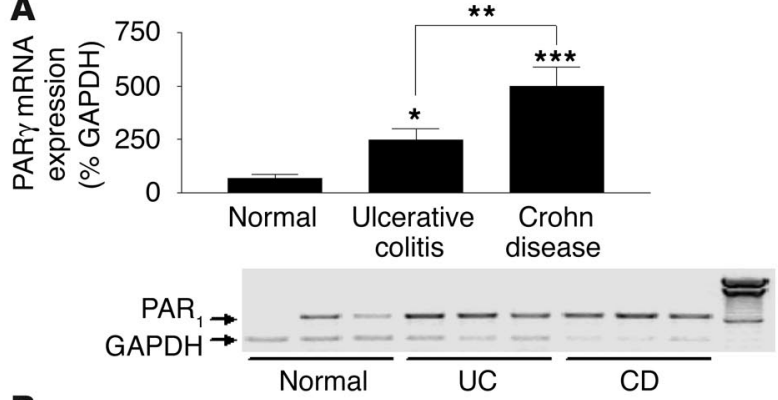

B
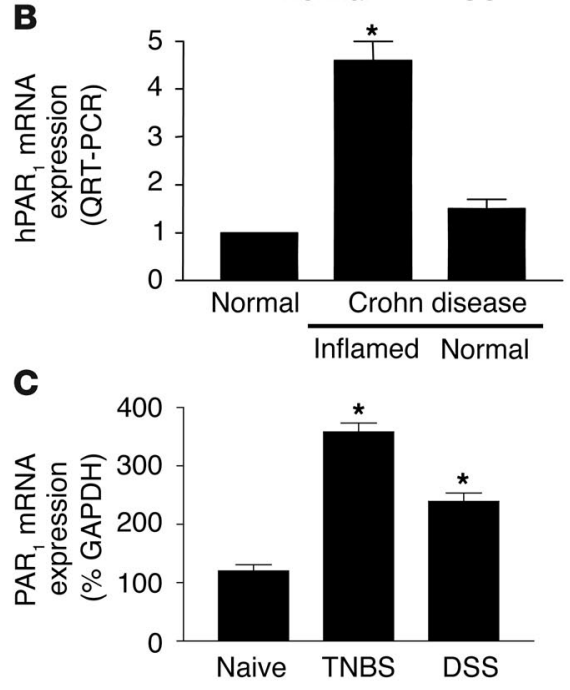

such as defects in barrier function, vascular supply, or enteric nerve function (22). Considering the proinflammatory effects observed upon $\mathrm{PAR}_{1}$ activation in different tissues or cells, the abundant expression of $\mathrm{PAR}_{1}$ in the gastrointestinal tract, and the fact that proteinases that activate $\mathrm{PAR}_{1}$ (not only thrombin and trypsin, but also pathogen-derived proteinases) are found in increased concentrations in the intestine of IBD patients $(23,24)$, we hypothesized that $\mathrm{PAR}_{1}$ activation in the intestine may be involved in the pathogenesis of IBD. To test this hypothesis, we first evaluated the abundance of $\mathrm{PAR}_{1}$ in colonic tissue biopsies from IBD patients. Upon finding an increase in $\mathrm{PAR}_{1}$ expression in those samples, we went on to assess the ability of a $\mathrm{PAR}_{1}$ agonist to cause an inflammatory response in the colon of both normal and $\mathrm{PAR}_{1}$-deficient $\left(\mathrm{PAR}_{1}{ }^{-/-}\right)$ mice. We then characterized the $\mathrm{PAR}_{1}$-induced colitis, investigating the involvement of permeability, apoptosis, and lymphocyte functions. Further, we used 2 murine models of colitis induced by the intracolonic administration of trinitrobenzene sulfonic acid (TNBS) and dextran sodium sulfate (DSS) to evaluate whether $\mathrm{PAR}_{1}$ antagonism protects against colitis development. Finally, we compared the colonic inflammatory response induced by TNBS and DSS administration in WT and $\mathrm{PAR}_{1}{ }^{-/-}$mice. Our data support the hypothesis that $\mathrm{PAR}_{1}$ plays an important role in IBD.

\section{Results}

$P A R_{1}$ expression in the colon of IBD patients and mice with colitis. A PCR product of the predicted size of $708 \mathrm{bp}$ was amplified from RNA prepared from the colon of normal and IBD (ulcerative colitis and Crohn disease) patients, showing the presence of $\mathrm{PAR}_{1}$ in those tissues. Compared with the level of expression of $\mathrm{PAR}_{1}$ in

\section{Figure 1}

PAR1 mRNA detection in humans and mice. (A and B) PAR 1 mRNA detection in colonic biopsies from control (normal), ulcerative colitis (UC), or Crohn disease (CD) patients, by RT-PCR (A) and real-time RT-PCR (B). A minimum of 5 patients per group was considered for quantification, and representative RT-PCR for 3 patients per group is shown (blots). hPAR ${ }_{1}$, human $\mathrm{PAR}_{1}$. (C) $\mathrm{PAR}_{1}$ mRNA detection in colonic tissues from naive mice or mice with TNBS- or DSS-induced colitis. PAR 1 mRNA detection was assessed by the amplification of a specific PCR fragment and was expressed as percentage of amplified GAPDH fragment. For quantification, values are mean \pm SEM; $n=5$ per group. ${ }^{\star} P<0.05,{ }^{\star \star} P<0.01,{ }^{* \star *} P<0.001$.

normal colon, the level of expression of $\mathrm{PAR}_{1}$ was significantly higher in IBD patients (Figure 1A). In Crohn disease patients, a 7 -fold increase in the level of $\mathrm{PAR}_{1}$ expression was observed compared with that in normal colons. $\mathrm{PAR}_{1}$ expression in ulcerative colitis patients was increased 3.5-fold compared with that in normal colon. Histological assessment confirmed the endoscopic and clinical diagnosis of IBD in all such subjects and confirmed the endoscopically normal-appearing mucosa in those undergoing screening colonoscopies. Real-time RT-PCR confirmed the overexpression of $\mathrm{PAR}_{1}$ in the same tissues as shown in Figure 1A (not shown). Moreover, in other Crohn disease patients, we showed using real-time PCR that $\mathrm{PAR}_{1}$ overexpression was restricted to inflamed colonic tissues (Figure 1B). In the colon of mice that developed colitis after intracolonic administration of TNBS or DSS, $\mathrm{PAR}_{1}$ mRNA expression was also upregulated compared with that in naive controls (Figure 1C).

Immunolocalization of $\mathrm{PAR}_{1}$ in colons from Crohn disease patients showed that $\mathrm{PAR}_{1}$ in noninflamed areas was mainly located on endothelial cells of the submucosal vessels (Figure 2A, arrows). Smooth muscle cells also showed some immunoreactivity for $\mathrm{PAR}_{1}$ (Figure $2 \mathrm{~A}$, arrowhead). $\mathrm{PAR}_{1}$ staining was abrogated in endothelial and smooth muscle cells by addition of $\mathrm{PAR}_{1}$ blocking peptide to the anti-PAR 1 antibody solution (Figure $2 \mathrm{~B}$; arrow indicates the same vessel as shown in Figure 2A). Extensive tissue necrosis was observed in tissue sections of a Crohn disease patient, taken from an inflamed part (Figure 2C). Here again, $\mathrm{PAR}_{1}$-stained cells were revealed on vessels (Figure 2C, arrow) and in lymphomonocytic cells infiltrated in the lamina propria (Figure 2C, inset). At a higher magnification (Figure 2D), endothelial cells (arrows) and inflammatory cells in the blood vessel lumen stained positive for $\mathrm{PAR}_{1}$. In the colon of mice, $\mathrm{PAR}_{1}$ expression was detected in normal tissues with staining of the epithelium surface (Figure 2E, arrows) and some blood vessels (not shown). In inflamed tissues (7 days after the induction of colitis), $\mathrm{PAR}_{1}$ was upregulated with a prominent expression by infiltrated cells of the lamina propria (Figure $2 \mathrm{~F}$, arrowheads), while the addition of the blocking peptide to this condition showed no staining for $\mathrm{PAR}_{1}$ (Figure $2 \mathrm{G}$ ). Disrupted staining for $\mathrm{PAR}_{1}$ on epithelial surfaces (Figure 2F, arrows) highlighted mucosal erosion due to TNBS-induced colitis. At a higher magnification (400), immunoreactivity for $\mathrm{PAR}_{1}$ revealed staining in infiltrated inflammatory cells (Figure $2 \mathrm{H}$ ).

Proinflammatory effects of $P A R_{1}$ activation in mouse colon. When administered directly into the lumen of the colon of mice, the selective $\mathrm{PAR}_{1}$ agonist TFLLR- $\mathrm{NH}_{2}$ caused time-dependent damage of the colon, with a maximal effect 24 hours after its administration (Figure $3 \mathrm{~A})$. The $\mathrm{PAR}_{1}$ agonist-induced damage observed 

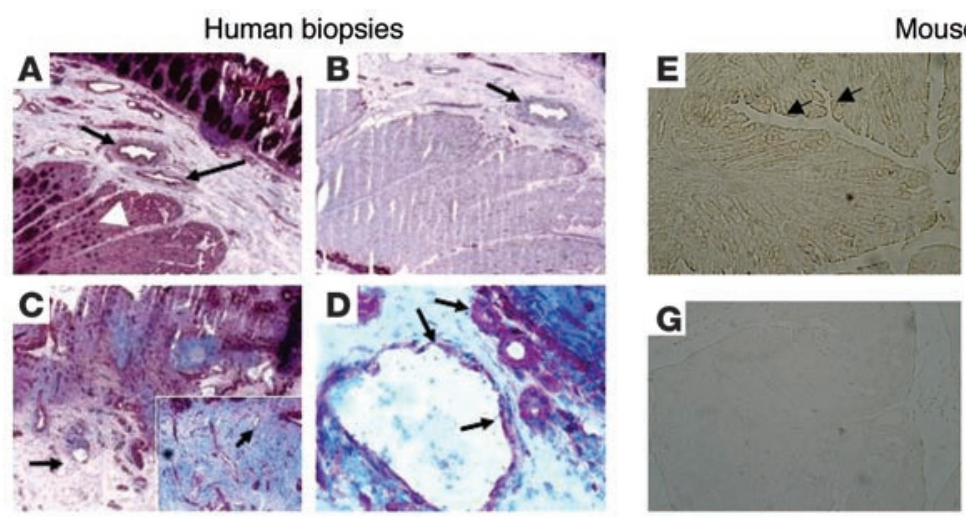

Mouse colon

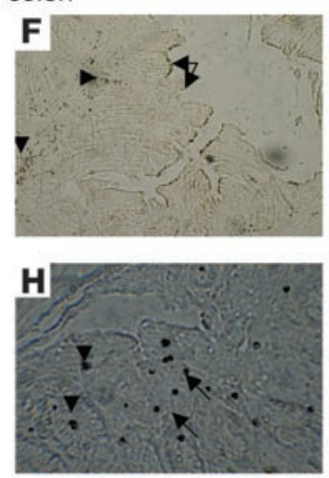

\section{Figure 2}

Immunohistolocalization of $\mathrm{PAR}_{1}$ protein expression in the muscularis mucosae of human colon (A-D) and in whole colonic tissues from naive mice $(\mathbf{E})$ and mice with TNBS-induced colitis $(\mathbf{F}-\mathbf{H})$. (A) Human biopsy section obtained from a macroscopically normal colon resected from a patient diagnosed with Crohn disease. $\mathrm{PAR}_{1}$ immunoreactivity was observed in vessels (arrows) and smooth muscle cells (arrowhead) (original magnification, $\times 100)$. (B) The same tissue incubated with a blocking peptide for the anti-PAR antibody $_{1}$ (original magnification, $\times 100$ ). PAR $_{1}$ staining on the vessel was inhibited (arrow). (C) Tissues of the same patient collected in a macroscopically inflamed area, showing extensive necrosis and inflammatory infiltration

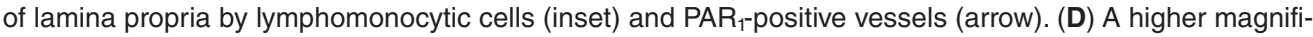
cation $(\times 400)$ of the vessel shown in C (arrows). Infiltrated inflammatory cells were observed in the lumen of the blood vessel. (E) Colonic tissues from naive mice, where $\mathrm{PAR}_{1}$ was expressed mainly on the epithelium (arrows). (F) Colonic tissues from TNBS-treated mice, with large tissue disruption, mucosal erosions (arrows), and PAR 1 staining in infiltrated cells of the lamina propria (arrowheads) as well as epithelium. (G) The PAR antibody was preincubated with a blocking peptide at $20 \mu \mathrm{g} / \mathrm{ml}$ to show specificity (original magnification, $\times 40)$. (H) A higher magnification of infiltrated cells of the lamina propria (arrows and arrowheads) positively stained for $\mathrm{PAR}_{1}$ (original magnification, $\times 400$ ).

24 hours after its intracolonic administration was dose-dependent (Figure 3B). Microscopically, the intracolonic injection of TFLLR-NH $\mathrm{N}_{2}$ provoked mucosal erosions (Figure 3C, arrowheads) and submucosal edema (arrows), while the control peptide had no effect (Figure 3D). Granulocyte infiltration, as observed by elevated myeloperoxidase (MPO) activity, was significantly increased 24 hours and 48 hours after a single intracolonic administration of TFLLR-NH $\mathrm{N}_{2}$ (Figure 3E) and declined to normal levels by 72 hours (not shown). The $\mathrm{PAR}_{1}$-activating peptide-induced increase in MPO activity was dose-dependent and started to show significant increase in granulocyte infiltration at doses that did not cause macroscopic damage, such as $50 \mu \mathrm{g}$ per mouse (Figure $3 \mathrm{~F}$ ). The effects of the control peptide, RLLFT- $\mathrm{NH}_{2}$, or vehicle on MPO activity (Figure 3E) and macroscopic-damage score (Figure 3A) were not significantly different from those in untreated mice. No significant increase in damage score or MPO activity was observed in $\mathrm{PAR}_{1}{ }^{-/-}$mice after the intracolonic administration of TFLLR$\mathrm{NH}_{2}$ (Figure 4), which demonstrates that $\mathrm{PAR}_{1}$ activation is responsible for the tissue-damaging effects of the $\mathrm{PAR}_{1}$ agonist.

Mechanisms involved in $P A R_{1}$-induced colitis. In contrast to $\mathrm{PAR}_{2}$ induced colitis (25), the proinflammatory effects of $\mathrm{PAR}_{1}$-activating peptide did not involve activation of capsaicin-sensitive sensory nerves, or activation of neurokinin-1 (NK-1) receptors, since no significant inhibition of the inflammatory response (macroscopic-damage score and MPO activity) was observed in mice that had been pretreated with capsaicin, or with the NK-1 antagonist SR140333 (data not shown).

Since PAR 1 agonists have been shown to induce increased intestinal permeability in vivo (17), we wanted to investigate whether or not $\mathrm{PAR}_{1}$-induced intestinal barrier breakage was was still significantly higher than in saline-administered mice, demonstrating only a partial inhibition of MPO activity by ML-7 pretreatment.

In order to assess the role of $\mathrm{B}$ and $\mathrm{T}$ lymphocytes in $\mathrm{PAR}_{1}$ agonist-induced colitis, we investigated the effect of TFLLR- $\mathrm{NH}_{2}$ administration in the colon of immunodeficient mice. SCID mice are homozygous for the severe combined immunodeficiency mutation, which is characterized by the absence of functional $\mathrm{T}$ and $\mathrm{B}$ cells, lymphopenia, and hypogammaglobulinemia. RAG1/mice, which have undergone a targeted deletion of the recombination-activating gene 1 , lack mature $B$ and $T$ lymphocytes. In both SCID and $\mathrm{RAG}^{-/-}$mice, daily intracolonic administration of the $\mathrm{PAR}_{1}$-activating peptide TFLLR-NH $\mathrm{N}_{2}$ for 7 days $(50 \mu \mathrm{g} / \mathrm{mouse})$ failed to induce inflammation (macroscopic-damage score, MPO activity, and increased wall thickness), compared with administra-

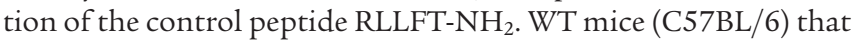
received intracolonically the $\mathrm{PAR}_{1}$-activating peptide TFLLR-NH showed a significant increase in damage score, MPO activity, and wall thickness (Figure 5, D-F).

$P A R_{1}$ activation exacerbates inflammation in a mouse model of IBD. Intracolonic administration of TNBS $(1 \mathrm{mg} / \mathrm{kg})$ resulted in weight loss (Figure 6A), increased damage score (Figure 6B), and increased MPO activity (Figure 6C). Daily intracolonic administration of the selective $\mathrm{PAR}_{1}$-activating peptide TFLLR-NH $\mathrm{N}_{2}$ further reduced body weight after TNBS administration, compared with that of mice treated with the control peptide or saline (Figure 6A). Macroscopic-damage score and colonic MPO activity levels were increased in mice that had also received a daily intracolonic injection of the $\mathrm{PAR}_{1}$ agonist (Figure 6, B and C) after the induction of TNBS colitis, compared with those in TNBS-treated mice administered daily with the control peptide or saline. Daily 


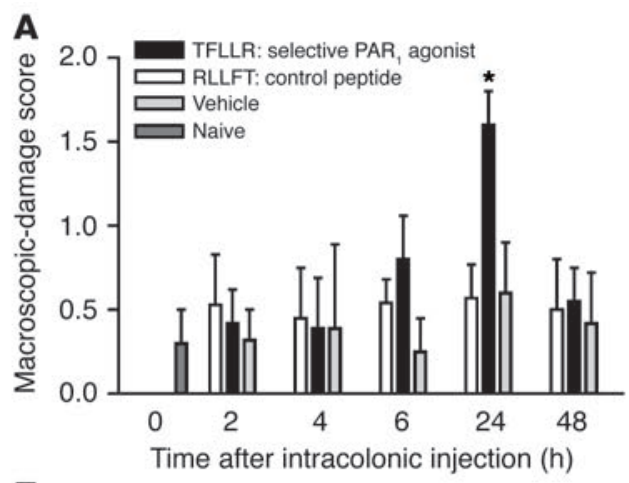

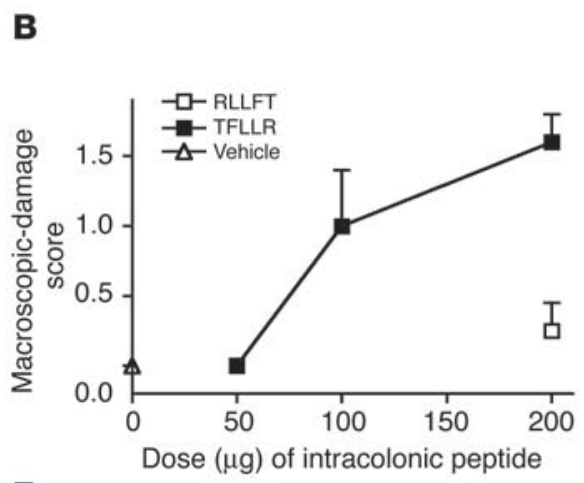

$\mathbf{F}$

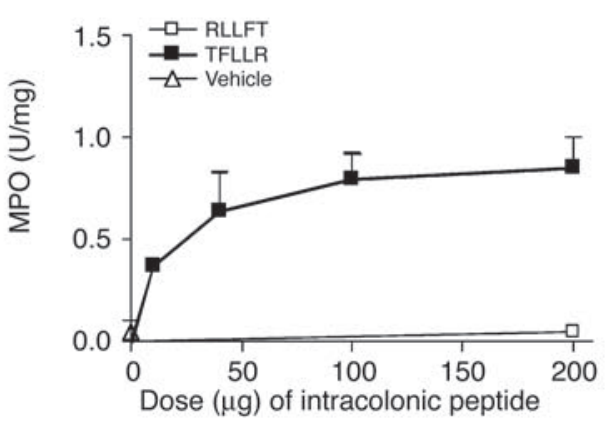

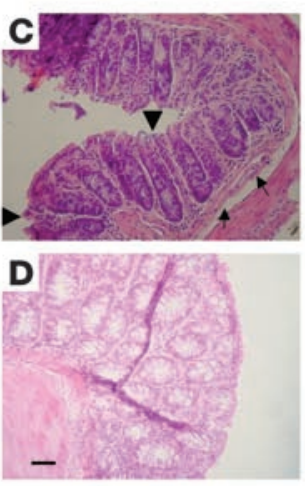

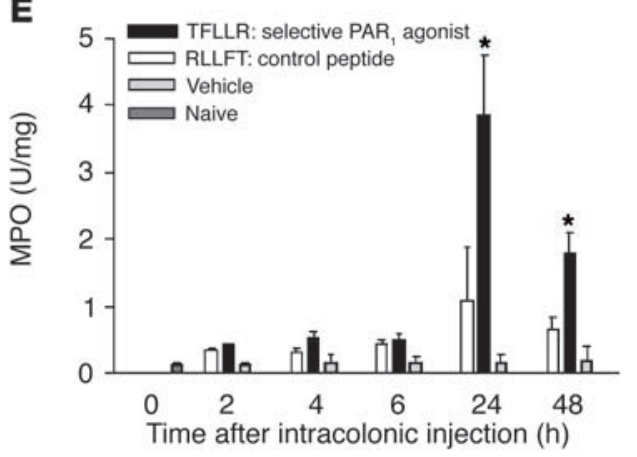

Figure 3

Kinetic and dose-response curves of macroscopic-damage score ( $\mathbf{A}$ and $\mathbf{B}$ ) and myeloperoxidase (MPO) activity (E and $\mathbf{F})$ induced by the intracolonic administration of the PAR -activating peptide TFLLR- $\mathrm{NH}_{2}$, the control peptide RLLFT-NH , $_{2}$ or their vehicle, in C57BL/6 mice. (C and $\mathbf{D}$ ) Representative H\&E-stained histological sections of colons from WT mice that have received an intracolonic administration of TFLLR-NH ${ }_{2}$ (C) or RLLFT-NH ${ }_{2}$ (D). Values are mean $\pm \mathrm{SEM} ; n=8$ per group. *Significantly different from RLLFT-NH ${ }_{2}$-treated group, $P<0.05$. Dose-response and histological sections were performed at the 24-hour time point after the intracolonic administration of RLLFT-NH or TFLLR-NH $_{2}$. Scale bar: $15 \mu \mathrm{m}$ (applies to $\mathbf{C}$ and $\mathbf{D}$ ). In $\mathbf{C}$, arrowheads show mucosal erosion, and arrows show submucosal edema.

systemic treatment (i.p.) with the $\mathrm{PAR}_{1}$ agonist TFLLR-NH $\mathrm{N}_{2}$ did not induce changes in body weight, macroscopic-damage score, or MPO activity after the induction of colitis, compared with those in mice treated with the control peptide or vehicle (not shown).

Anti-inflammatory effects of $P A R_{1}$ antagonist in 2 mouse models of $I B D$. C57BL/6 mice were used for all the previous studies, because $\mathrm{PAR}_{1}{ }^{-/}$mice were raised in a $\mathrm{C} 57 \mathrm{BL} / 6$ background. However, $\mathrm{BALB} / \mathrm{c}$ mice, which are more susceptible to TNBS-induced colitis, are more widely accepted as an animal model of IBD (26). In order to test the effect of a $\mathrm{PAR}_{1}$ antagonist on the development of colitis, we wanted to use the most challenging and reliable animal model. For this reason, we chose to induce TNBS colitis in BALB/c mice treated or not treated with the $\mathrm{PAR}_{1}$ antagonist. Intracolonic administration of $2 \mathrm{mg} / \mathrm{kg}$ of TNBS in BALB/c mice resulted in high mortality rates: only $50 \%$ of mice survived for 7 days after the induction of colitis (Figure 7A). Daily treatment of mice with a $\mathrm{PAR}_{1}$ antagonist at doses of 3 and $5 \mathrm{mg} / \mathrm{kg}$ reduced the mortality by $20 \%$ and $30 \%$, respectively. In the same mice, granulocyte infiltration, as measured by MPO activity, was significantly attenuated in a dose-dependent manner by treatment with the $\mathrm{PAR}_{1}$ antagonist (Figure 7B). In order to assess further the ability of the $\mathrm{PAR}_{1}$ antagonist to mitigate the development of colitis, we used a lower dose of TNBS $(1 \mathrm{mg} / \mathrm{kg})$, which produced a lower mortality. The decrease in weight gain observed in mice after the intracolonic administration of $1 \mathrm{mg} / \mathrm{kg}$ of TNBS was reversed by treatment with the $\mathrm{PAR}_{1}$ antagonist at a dose of $5 \mathrm{mg} / \mathrm{kg}$ (Figure $7 \mathrm{C}$ ). The increased macroscopic- and microscopic-damage scores and MPO activity were also significantly attenuated by daily treatment

\section{Figure 4}

Macroscopic-damage score (A) and MPO activity (B) induced by the intracolonic administration of the $\mathrm{PAR}_{1-}$ activating peptide TFLLR- $\mathrm{NH}_{2}(200$ $\mu \mathrm{g} /$ mouse) in $\mathrm{PAR}_{1}$-deficient mice $\left(\mathrm{PAR}_{1}{ }^{--}\right)$and their WT littermates $\left(\mathrm{PAR}_{1}{ }^{+++}\right)$, compared with naive mice (time 0 ). Values are mean \pm SEM; $n=8$ per group. *Significantly different from naive mice (time 0 ) of the corresponding genotype, $P<0.05$.
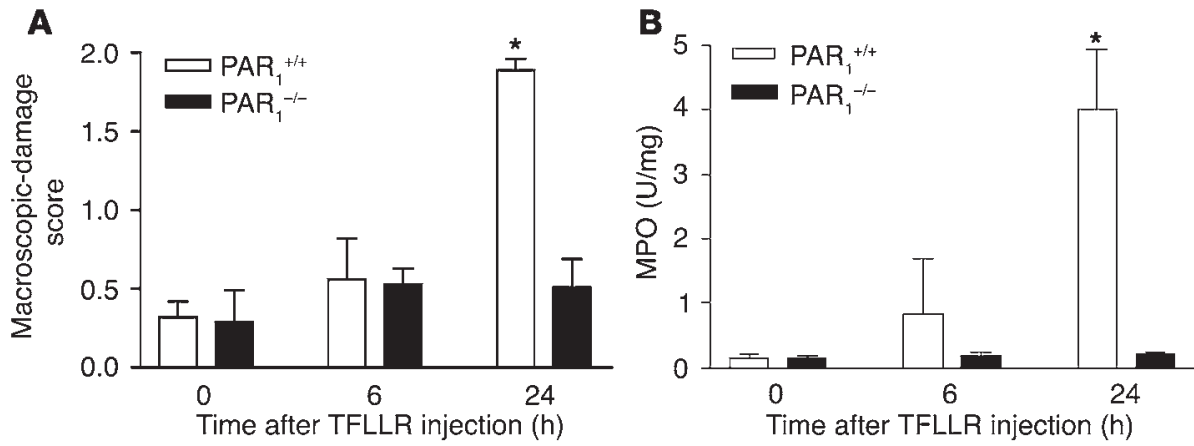

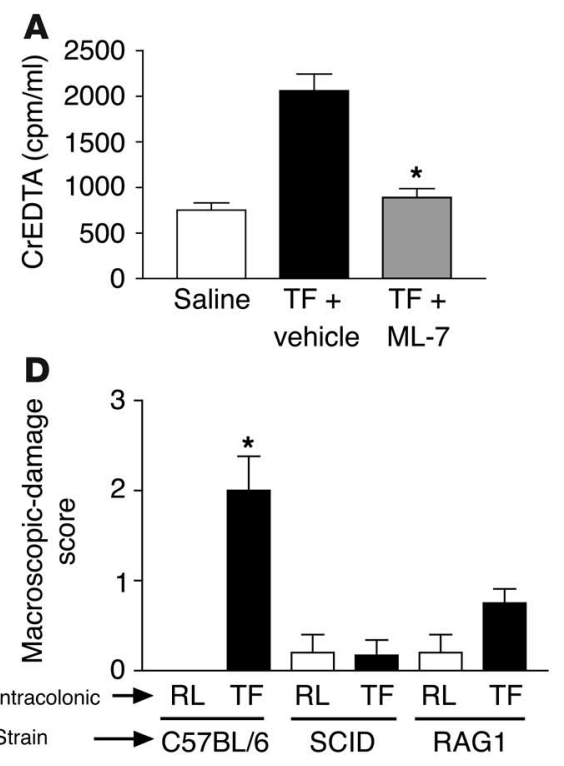

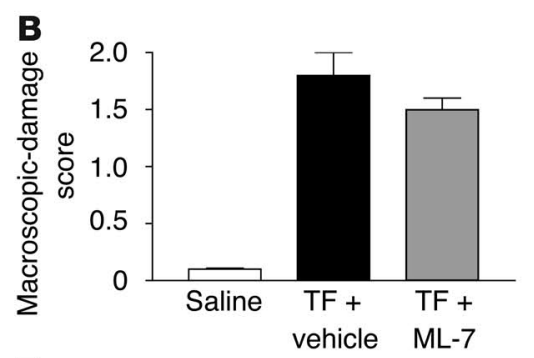

E

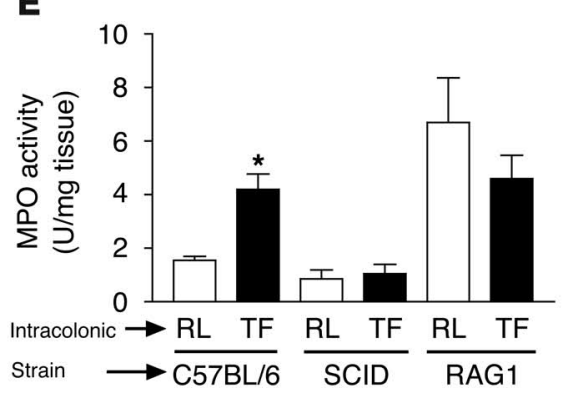

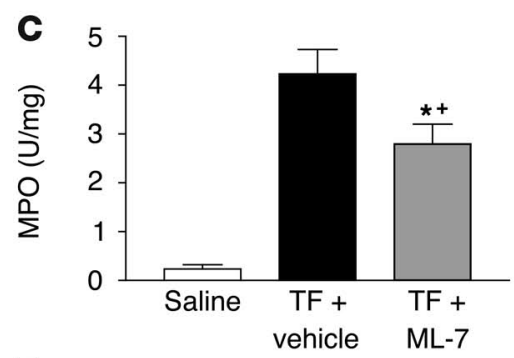

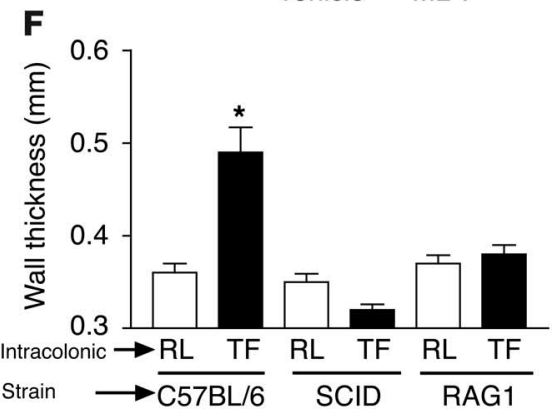

Figure 5

Effects of vehicle or MLCK inhibitor (ML-7) pretreatment on changes in permeability (passage of EDTA radiolabeled with Chromium-51 [CrEDTA; Amersham Biosciences] from the intestinal lumen to the blood) (A), macroscopic-damage score (B), and MPO activity (C) in mice that have received intracolonically the $\mathrm{PAR}_{1}$-activating peptide TFLLR-NH $\mathrm{N}_{2}$ or saline. (D-F) Macroscopic-damage score (D), MPO activity (E), and wall thickness $(\mathrm{F})$ in the colon of WT (C57BL/6), SCID, or RAG ${ }^{-1}$ mice. Values are mean \pm SEM; $n=8$ per group. *Significantly different from vehicletreated mice for $\mathbf{A}-\mathbf{C}$, and from mice treated with control peptide $\left(\mathrm{RLLFT}-\mathrm{NH}_{2}\right)$ for $\mathbf{D}-\mathbf{F}, P<0.05$. ${ }^{+}$Significantly different from saline-treated mice, $P<0.01$. TF, TFLLR-NH $\mathrm{N}_{2} ; \mathrm{RL}, \mathrm{RLLFT}-\mathrm{NH}_{2}$.

with $5 \mathrm{mg} / \mathrm{kg}$ of the $\mathrm{PAR}_{1}$ antagonist (Figure 7, D-F). We then used another model of colitis induced by addition of DSS in drinking water of BALB/c mice. DSS administration was associated with significant clinical changes, including weight loss (starting on day 2 ), the appearance of occult fecal blood (on day 3), and diarrhea (on day 4) (Figure 7, G-I). In contrast, administration of $\mathrm{PAR}_{1}$ antagonist at the dose of $5 \mathrm{mg} / \mathrm{kg}$ resulted in a significant amelioration of the severity of DSS colitis by day 7 , as shown by an approximately $60 \%$ reduction in the clinical disease activity index (Figure 7I). Compared with colons from mice given regular water, colons from mice receiving DSS in their drinking water for 7 days showed extensive cellular infiltrate, submucosal edema, and large areas of epithelial erosion (not shown). In contrast, histologi- cal analysis of colons from DSS-treated mice receiving the $\mathrm{PAR}_{1}$ antagonist showed reduced numbers of infiltrating cells; these mice were largely protected from DSS-associated mucosal injury and edema (not shown).

We also evaluated the influence of the $\mathrm{PAR}_{1}$ antagonist on the production of cytokines that are mechanistically linked to TNBSinduced colitis, comparing the expression of TNF- $\alpha$ and IFN- $\gamma$ in the colons of colitic mice treated with the $\mathrm{PAR}_{1}$ antagonist or vehicle. As shown in Figure 8, treatment with the $\mathrm{PAR}_{1}$ antagonist at the highest dose $(5 \mathrm{mg} / \mathrm{kg})$ significantly inhibited the expression of TNF- $\alpha$ and IFN- $\gamma$ protein (Figure 8, A and B) and mRNA (Figure $8 \mathrm{C})$. Furthermore, the $\mathrm{PAR}_{1}$ antagonist significantly attenuated the TNBS-induced increase of expression of mRNA for IL-2, COX-2,
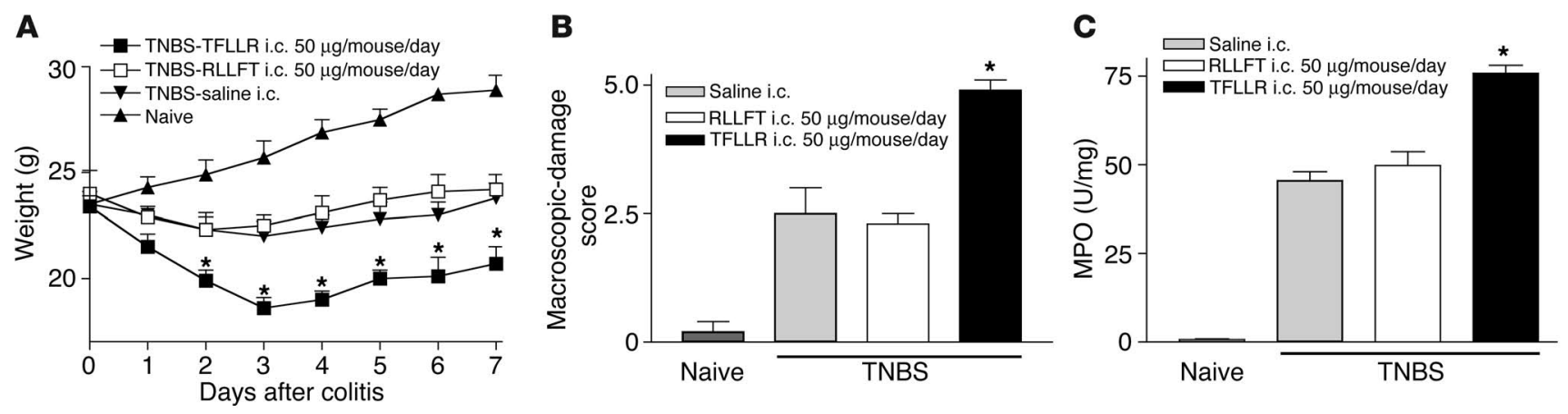

Figure 6

Effects of intracolonic (i.c.) administration of $\mathrm{PAR}_{1}$-activating peptide TFLLR-NH $\mathrm{N}_{2}$, control peptide RLLFT-NH $\mathrm{N}_{2}$, or their vehicle (saline) on weight (A), macroscopic-damage score (B), and MPO activity (C), in C57BL/6 mice that have received an intracolonic administration of TNBS (1 mg/

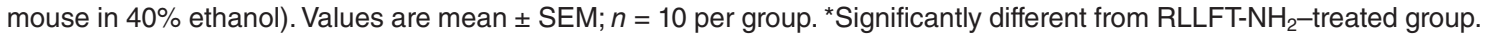


A

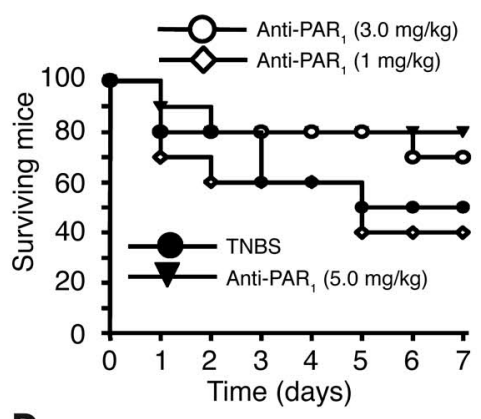

D

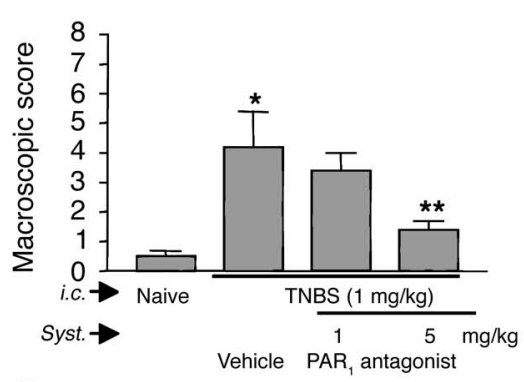

G

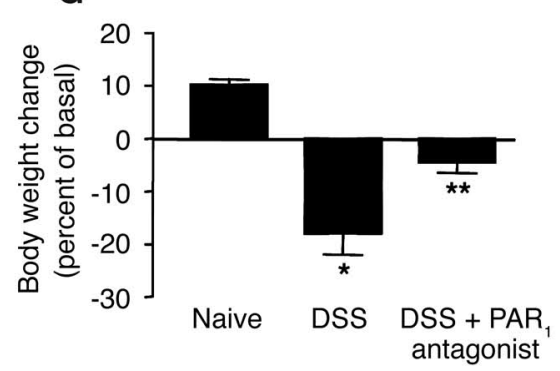

B

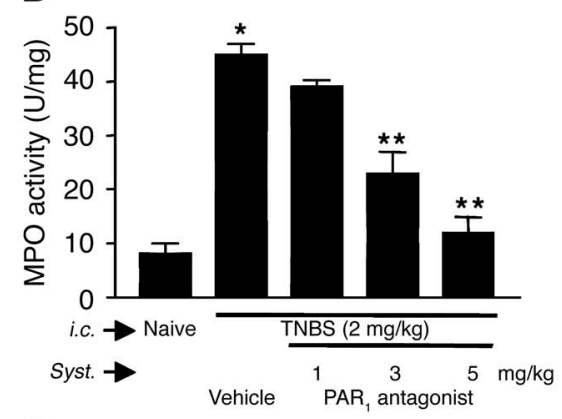

E

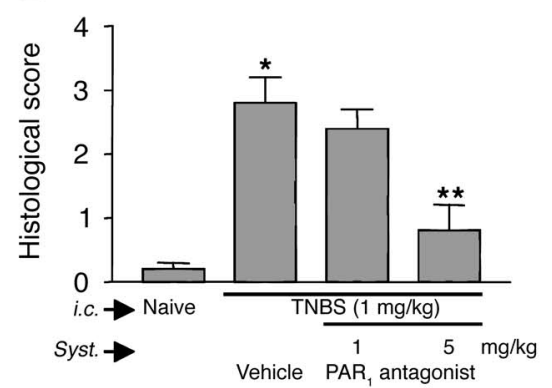

H

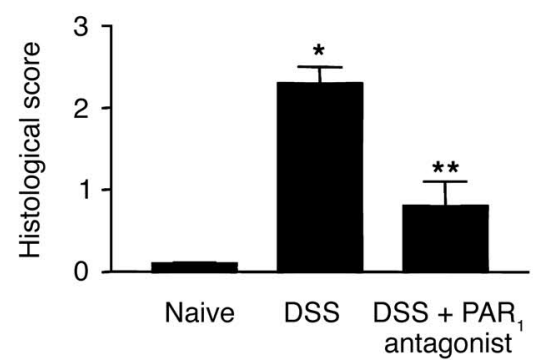

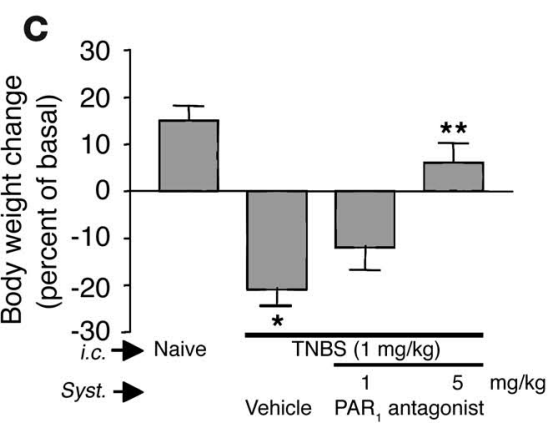

F
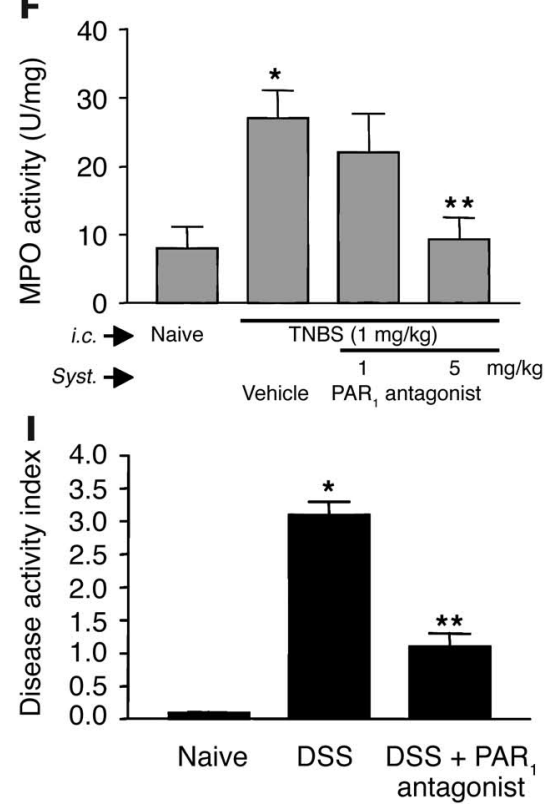

Figure 7

Effect of systemic (Syst.) treatment with a PAR 1 antagonist on survival rate (A), MPO activity (B and $\mathbf{F})$, body weight (C and $\mathbf{G})$, macroscopic- and microscopic-damage score (D, E, and $\mathbf{H}$ ), and disease activity (I) in BALB/c mice, 7 days after the induction of colitis by intracolonic administration of TNBS at the dose of $2 \mathrm{mg}$ per mouse in $50 \%$ ethanol (A and B) or at the dose of $1 \mathrm{mg} / \mathrm{kg}$ in $50 \%$ ethanol (C-F), or 8 days after the induction of DSS colitis $(\mathbf{G}-\mathbf{I})$. Values are mean $\pm \mathrm{SEM} ; n=12$ per group. *Significantly different from naive group; ** significantly different from vehicle-treated group.

and iNOS in the colon (Figure 8C). The levels of TNF- $\alpha$, IL-12, and IFN- $\gamma$ protein expression were also significantly reduced in mice with DSS-induced colitis that were treated with the $\mathrm{PAR}_{1}$ antagonist; this shows that the inhibitory effects of $\mathrm{PAR}_{1}$ antagonist are not limited to the TNBS model (Figure 8D). Since the levels of TNF- $\alpha$ and IFN- $\gamma$ release were significantly reduced in the colon of mice treated with the $\mathrm{PAR}_{1}$ antagonist after the induction of colitis, we next investigated whether or not treatment with the $\mathrm{PAR}_{1}$ antagonist would reduce the reactivity of lamina propria mononuclear cells (LPMCs). As observed in cells isolated from control mice, CD3/ CD28 cross-linking stimulated cytokine production (TNF- $\alpha$ and IFN- $\gamma$ ) from LPMCs (Figure 9; $n=4-5 ; P<0.05$ versus untreated). After the induction of colitis by the intracolonic administration of TNBS, isolated LPMCs not only released more TNF- $\alpha$ and IFN- $\gamma$ under basal conditions ( $n=4-5 ; P<0.05$ versus unstimulated) but exhibited a 4-fold increase in the release of TNF- $\alpha$ and IFN- $\gamma$ compared with control cells, after anti-CD3/anti-CD28 stimulation (Figure 9; $n=4-5 ; P<0.01$ ). Strikingly, LPMCs obtained from mice treated with TNBS plus $\mathrm{PAR}_{1}$ antagonist generated significantly lower amounts of TNF- $\alpha$ and IFN- $\gamma$ in response to costimulatory molecules (anti-CD3/anti-CD28) $(n=4-5 ; P<0.01$ versus TNBS alone). Those amounts were comparable to the level of TNF- $\alpha$ and IFN- $\gamma$ release by LPMCs from noninflamed tissues (Figure 9). In LPMCs isolated from noninflamed tissues, exposure to the $\mathrm{PAR}_{1}$ agonist TFLLR induced a significant increase in IFN- $\gamma$ release to the same extent as in cells stimulated by anti-CD3/anti-CD28. When added together, $\mathrm{PAR}_{1}$ agonist and anti-CD3/anti-CD28 provoked an even larger release of IFN- $\gamma$ (Figure 9C). In cells obtained from TNBS-treated mice, $\mathrm{PAR}_{1}$ agonist was also able to increase significantly the release of IFN- $\gamma$ compared with that in cells incubated with the medium alone (Figure 9C).

$P A R_{1}$ activation is involved in the pathogenesis of experimental IBD. Since the experiments with the $\mathrm{PAR}_{1}$ antagonist showed that inhibition of $\mathrm{PAR}_{1}$ could result in a decreased susceptibility to colitis, we next used $\mathrm{PAR}_{1}$-deficient $\left(\mathrm{PAR}_{1}{ }^{-/}\right)$mice to determine whether the presence of functional $\mathrm{PAR}_{1}$ was required for the pathogenesis of colitis in the TNBS model. We first established that $\mathrm{PAR}_{1}{ }^{-/-}$mice do not differ from their littermates in general health, and that no differences in the morphological or histological appearance could be detected in the colon of $\mathrm{PAR}_{1}{ }^{-/-}$mice 
A
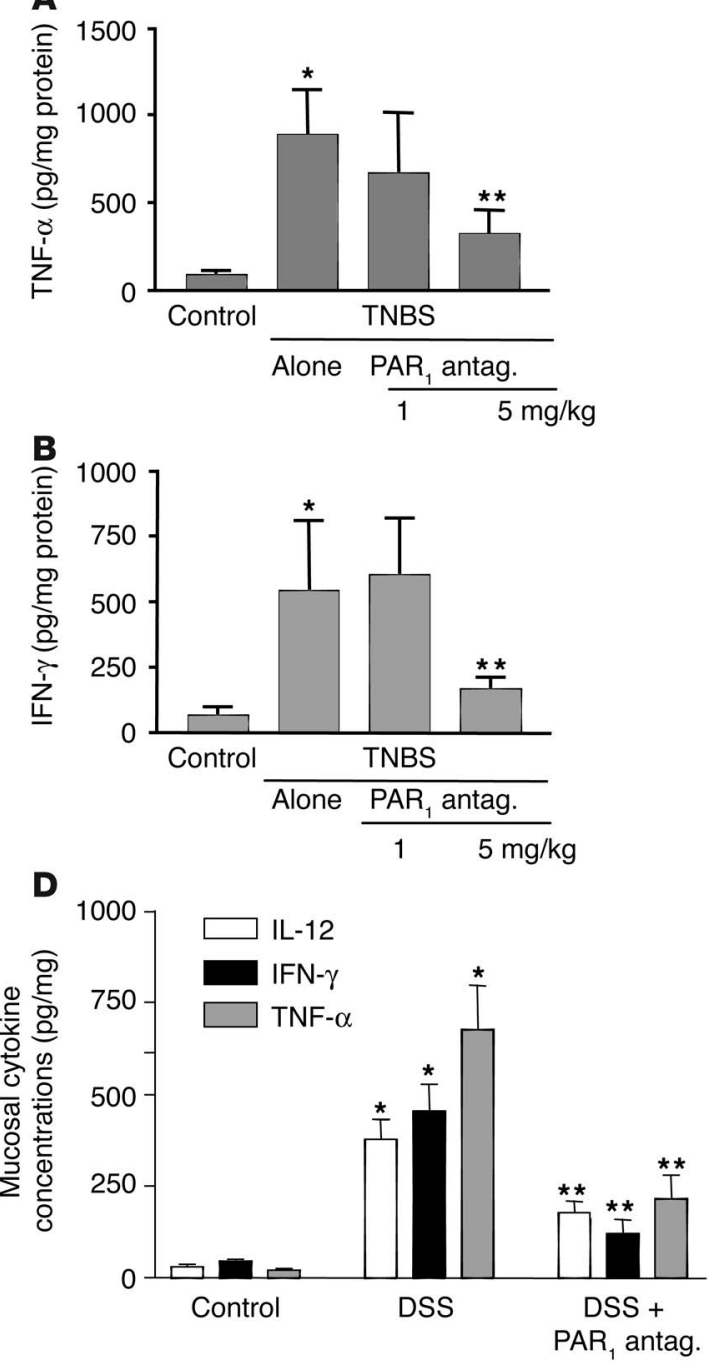

C
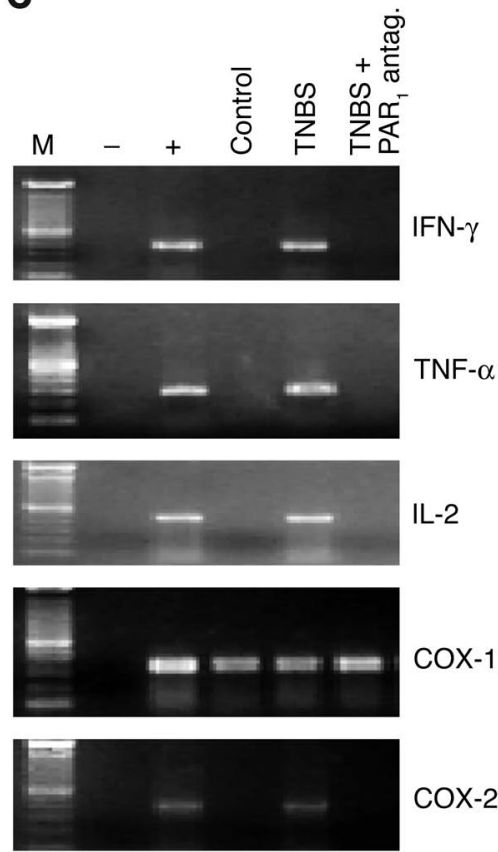

$\operatorname{cox}-2$

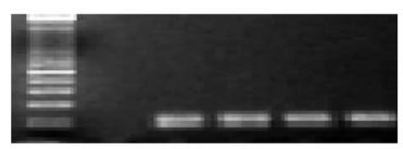

cNOS

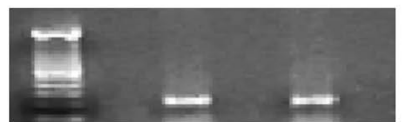

iNOS

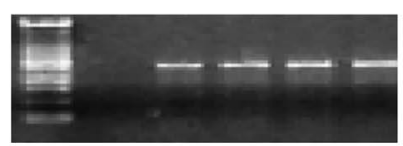

$\beta$-actin

\section{Figure 8}

TNF- $\alpha$ (A and D), IFN- $\gamma$ (B and D), and IL-12 (D) protein expression, and IFN- $\gamma$, TNF- $\alpha$, IL-2, COX-1, COX-2, constitutive NO synthase (cNOS), iNOS, and $\beta$-actin mRNA levels (C), in the colon of BALB/c naive mice, TNBS- and $\mathrm{PAR}_{1}$ antagonist-treated mice, or TNBS- and vehicle-treated mice $(\mathbf{A}-\mathbf{C})$, or in the colon of BALB/ $C$ naive mice, mice treated with DSS plus vehicle, or mice treated with DSS plus $\mathrm{PAR}_{1}$ antagonist (D). For A, B, and $\mathbf{D}$, protein content of the mouse colon was determined by ELISA, and values are mean \pm SEM; $n=12$ per group. *Significantly different from naive group; ** significantly different from vehicle-treated group. For C, RT-PCR mRNA amplification was representative of 12 mice per group for each mediator. compared with their littermate controls (Figure 10). Relative to WT mice $\left(\mathrm{C} 57 \mathrm{BL} / 6, \mathrm{PAR}_{1}{ }^{++}\right)$, TNBS induced less severe colitis in $\mathrm{PAR}_{1}{ }^{-/}$mice, as shown by the comparison of survival rate (Figure 11A), weight gain (Figure 11B), macroscopic-damage score (Figure 11C), histological examination (Figure 10), and MPO activity (Figure 11D). The intracolonic administration of different concentrations of ethanol and TNBS led to different degrees of inflammation (Figure 11, C and D). When the DSS-induced colitis model was used, $\mathrm{PAR}_{1}{ }^{-/}$mice also showed a reduced macroscopic-damage score (Figure 11E), and reduced MPO activity (Figure 11F). For all of the inflammatory conditions tested, $\mathrm{PAR}_{1}{ }^{-/-}$mice demonstrated a significantly lower degree of inflammation (decreased damage score and MPO) than WT mice. These results suggest that $\mathrm{PAR}_{1}$ activation is an important component of the pathogenesis of both TNBS-induced and DSS-induced colitis.

\section{Discussion}

In view of the high level of $\mathrm{PAR}_{1}$ expression in the gastrointestinal tract (15), and the proinflammatory effects that have been described for $\mathrm{PAR}_{1}$ agonists in other tissues (4), we had as our working hypothesis that $\mathrm{PAR}_{1}$ activation might play a role in IBD.
Our first step in exploring this hypothesis was to evaluate the abundance of $\mathrm{PAR}_{1}$ expression in colonic tissues from patients with IBD (ulcerative colitis and Crohn disease) (Figure 1). We found a significant upregulation of $\mathrm{PAR}_{1}$ in both groups of patients, with a more marked increase in Crohn disease patients. These data could suggest that $\mathrm{PAR}_{1}$ expression is regulated by inflammatory signals in human colon, or that cells expressing $\mathrm{PAR}_{1}$ are infiltrated in inflammatory conditions. Our immunohistochemistry results showed that monocytic cells infiltrated in inflamed tissues from Crohn disease patients or in mouse submucosa expressed $\mathrm{PAR}_{1}$, which might then contribute to the overexpression of the receptor in inflamed tissues.

In keeping with our hypothesis of an involvement of $\mathrm{PAR}_{1}$ in colitis, we found that edema formation, epithelial damage, and granulocyte infiltration occurred following intracolonic administration of a $\mathrm{PAR}_{1}$-activating peptide to mice. We confirmed that the proinflammatory effects of the $\mathrm{PAR}_{1}$ agonist were mediated by $\mathrm{PAR}_{1}$ activation, given the lack of effect of $\mathrm{aAR}$ agonist in $\mathrm{PAR}_{1}$ deficient mice. Importantly, i.p. rather than local administration of a PAR $_{1}$-activating peptide did not induce colon inflammation (data not shown), which suggests that cells located in the colonic wall itself are involved in $\mathrm{PAR}_{1}$ agonist-induced colitis. In the intestine, 
A

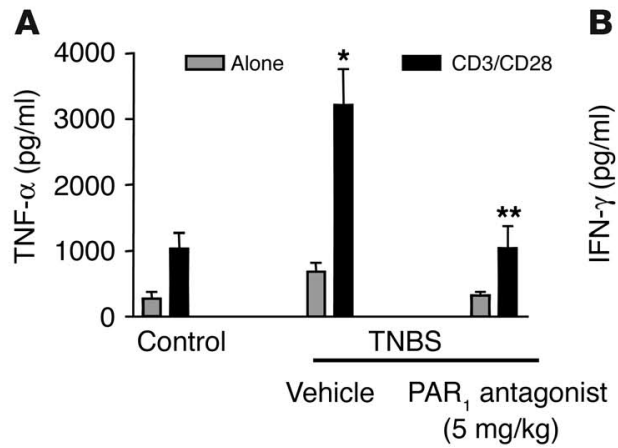

B

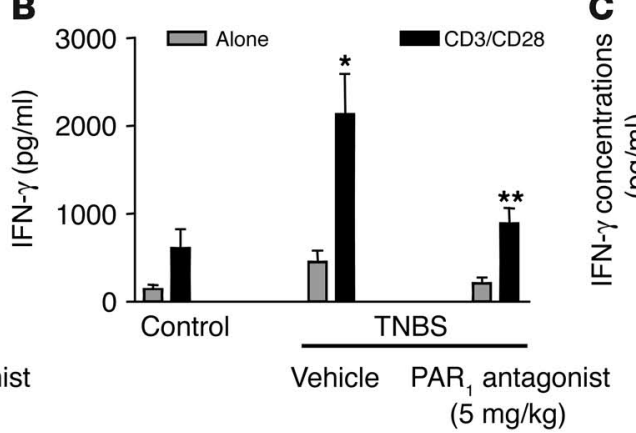

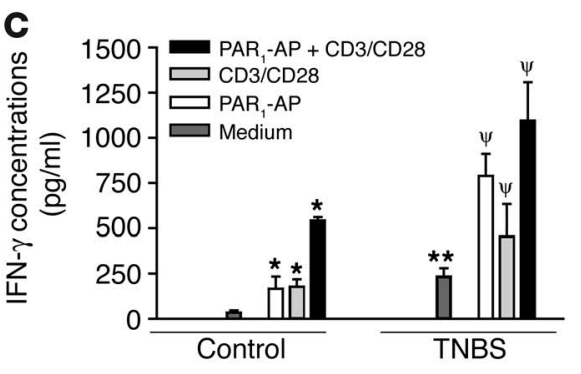

Figure 9

In vitro release of TNF- $\alpha(\mathbf{A})$ and IFN- $\gamma(\mathbf{B}$ and $\mathbf{C})$ by lamina propria monocytic cells that were left unstimulated (Alone) or stimulated with CD3 and

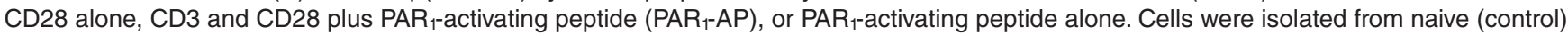
mice $(\mathbf{A}-\mathbf{C})$ or were isolated 7 days after intracolonic administration of TNBS from mice that had been treated with the PAR $\mathbf{R}_{1}$ antagonist $(\mathbf{A}$ and B) or with vehicle $(\mathbf{A}-\mathbf{C})$. Values are mean $\pm \mathrm{SEM} ; n=12$ per group. *Significantly different from control group in $\mathbf{A}$ and $\mathbf{B}$, and significantly different from medium alone in $\mathbf{C}$; ** significantly different from vehicle-treated group in $\mathbf{A}$ and $\mathbf{B}$, and from naive group in $\mathbf{C}$; ${ }^{*}$ significantly different from medium alone of cells from TNBS-treated mice.

$\mathrm{PAR}_{1}$ expression has been detected on neurons coexpressing inflammatory neuropeptides such as substance P (13), and a neurogenic mechanism involving capsaicin-sensitive fibers and NK-1 receptors has been revealed for $\mathrm{PAR}_{1}$ agonist-induced paw inflammation (27). Therefore, we considered that there might be a neurogenic component in $\mathrm{PAR}_{1}$ agonist-induced colitis. However, pretreatment with capsaicin or an NK-1 antagonist did not inhibit $\mathrm{PAR}_{1}$ agonist-induced colitis in mice, which suggests that $\mathrm{PAR}_{1}$ activation of sensory fibers and release of substance $\mathrm{P}$ are not involved in this process. $\mathrm{PAR}_{1}$ is expressed at the apical and basolateral membranes of enterocytes. When added either apically or basolaterally to monolayers of cultured enterocytes, $\mathrm{PAR}_{1}$ agonists increase permeability (17). Moreover, we have shown in mice that the intraluminal administration of $\mathrm{PAR}_{1}$ agonists can disrupt the integrity of the intestinal barrier, increasing paracellular permeability and allowing bacterial translocation into peritoneal organs (17). It can be hypothesized that $\mathrm{PAR}_{1}$ activation on enterocytes mediates intestinal barrier breakdown, which then allows pathogen penetration to cause further inflammation. However, our results show here that inhibition of $\mathrm{PAR}_{1}$ agonistinduced permeability does not necessarily inhibit $\mathrm{PAR}_{1}$-induced inflammation (Figure 5, A-C). Increased macroscopic-damage score was not inhibited by MLCK inhibitor treatment, which completely abolished $\mathrm{PAR}_{1}$-induced permeability. Granulocyte infiltration was only partially reduced by MLCK inhibitor treatment, which suggests that $\mathrm{PAR}_{1}$-induced intestinal barrier breakdown, although participating in $\mathrm{PAR}_{1}$-induced colitis, cannot be considered the major cause of this inflammation. $\mathrm{PAR}_{1}$ agonists have been shown to convey an apoptotic signal to enterocytes (17). It is also possible that $\mathrm{PAR}_{1}$ agonist-induced colitis may be mediated by increased apoptosis at the enterocyte level. This hypothesis is also in accordance with the observation of increased enterocyte apoptosis in IBD patients (28). However, here again, while $\mathrm{PAR}_{1}$ induced apoptosis has been shown to be responsible for increased permeability, the $\mathrm{PAR}_{1}$-induced increase in intestinal barrier permeability was not fully responsible for the inflammation observed. Our results indicate that $\mathrm{PAR}_{1}$-induced intestinal permeability and/or apoptosis can participate in the generation of colitis but cannot be considered the only factors responsible for this inflam- mation. In human normal epithelia, the status of $\mathrm{PAR}_{1}$ expression is not clear, as $\mathrm{PAR}_{1}$ has been detected in nontransformed epithelial cells (16) but not in the mucosa of control patients (18), and we have detected $\mathrm{PAR}_{1}$ in normal (noninflamed) tissues of Crohn disease patients, mostly in endothelial cells and smooth muscle cells. Thus, changes in permeability due to the possible activation of $\mathrm{PAR}_{1}$ on epithelial cells might not be as relevant in humans as they are in rodents, where $\mathrm{PAR}_{1}$ expression was found on the epithelial surface (Figure 2, E and F).

Although the single intraluminal administration of a $\mathrm{PAR}_{1}$ agonist is able to cause colon inflammation, this inflammation is limited in time (resolved by 72 hours) and extent, compared with that in well-established models of IBD, such as the TNBS model. While the response to injury in the normal colon involves an inflammatory response and then a resolution of this inflammation, in IBD patients, the response to injury is prolonged and
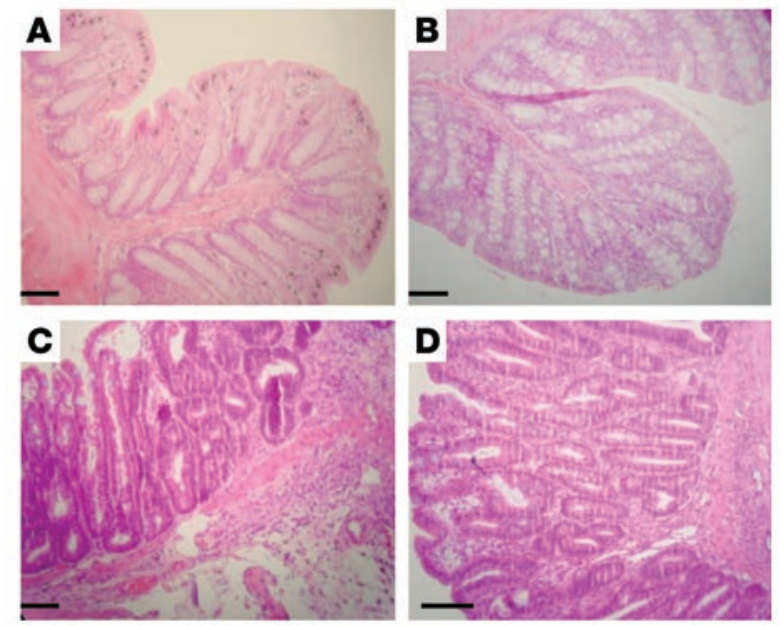

Figure 10

Representative H\&E-stained histological sections from WT (A and C)

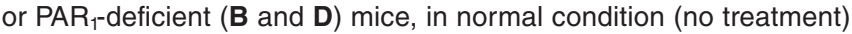
(A and $\mathbf{B}$ ) or 7 days after the intracolonic administration of TNBS (1 $\mathrm{mg} / \mathrm{kg}$ in 40\% ethanol) (C and D). Scale bars: $20 \mu \mathrm{m}$. 
A

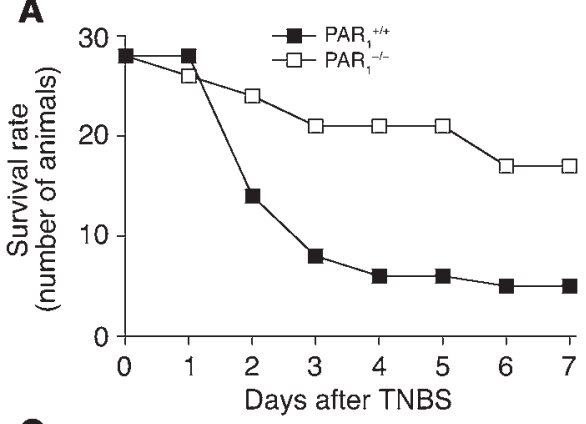

C

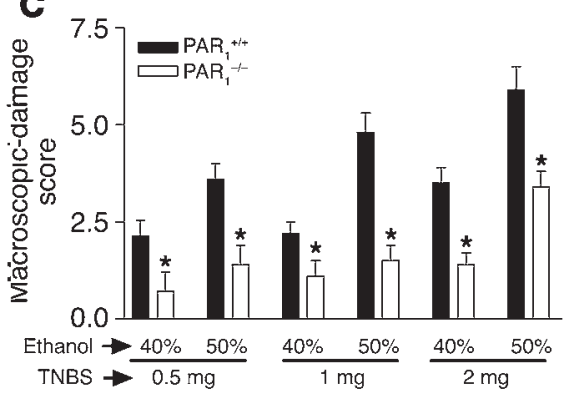

E

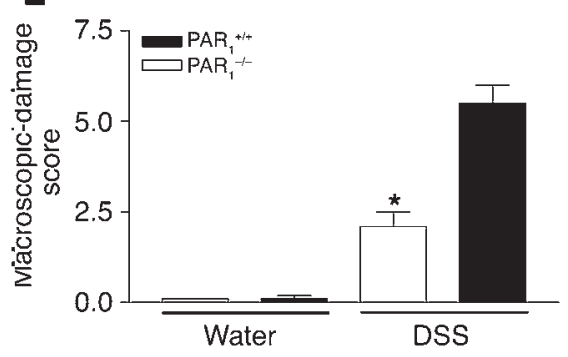

B

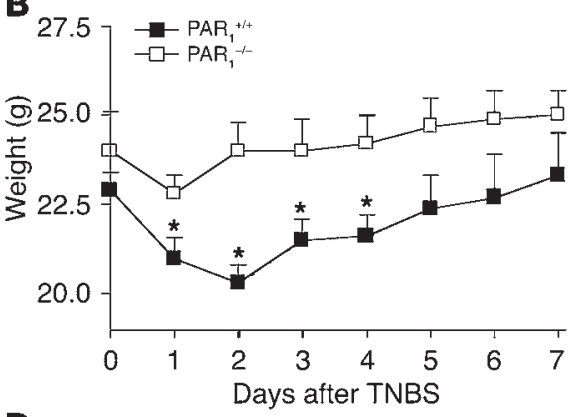

D

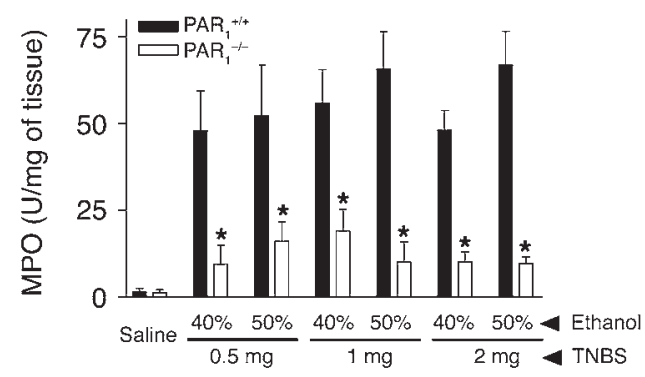

$\mathbf{F}$

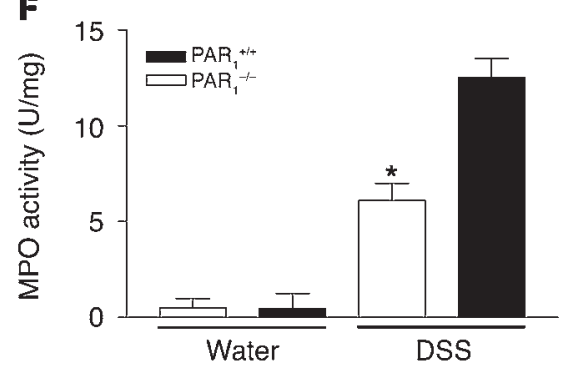

\section{Figure 11}

Effect of intracolonic TNBS administration (A-D) or DSS treatment (E and $\mathbf{F}$ ) on survival rate $(\mathbf{A})$, weight $(\mathbf{B})$, macroscopic-damage score (C and E), and MPO activity ( $\mathbf{D}$ and $\mathbf{F}$ ) in PAR $_{1}$-deficient mice $\left(\mathrm{PAR}_{1}^{---}\right)$and WT littermates $\left(\mathrm{PAR}_{1}{ }^{++}\right)$. Values are mean $\pm \mathrm{SEM}$; minimum of $n=10$ per group. *Significantly different from $\mathrm{PAR}_{1}{ }^{--}$in $\mathbf{B}$, and significantly different from WT in $\mathbf{C}-\mathbf{F}$, $P<0.05$. characterized by multiple recurrences. We hypothesized that chronic activation of $\mathrm{PAR}_{1}$ might prolong an established inflammation such as the chronic inflammatory response observed in IBD. In C57BL/ 6 mice, the intracolonic administration of TNBS induces a severe inflammatory response that reaches a maximum, in terms of granulocyte infiltration and mucosal damage, 72 hours later and declines thereafter (29). Daily injections of the $\mathrm{PAR}_{1}$ agonist appeared to impair the resolution of inflammation, as high levels of macroscopic damage and MPO activity were still evident 7 days after TNBS administration (Figure 4).

Using both a pharmacological and a gene-knockout approach, we have determined that the absence of functional $\mathrm{PAR}_{1}$ was beneficial for the prevention of colitis development in the TNBS and DSS models. Both in mice treated with the $\mathrm{PAR}_{1}$ antagonist and in $\mathrm{PAR}_{1}$-deficient mice, survival rates and weight gain were increased, while mucosal damage and granulocyte infiltration were reduced. Numerous mechanisms may be proposed to explain the involvement of $\mathrm{PAR}_{1}$ activation in the pathogenesis of this experimental model of colitis. As previously discussed, the PAR $_{1}$-mediated increase in intestinal permeability could contribute to pathogen infiltration and further development of inflammation but is not the only factor involved. The results generated with the $\mathrm{PAR}_{1}$ antagonist demonstrated that expression of the proinflammatory cytokines IFN- $\gamma$ and TNF- $\alpha$ was downregulated in response to $\mathrm{PAR}_{1}$ inhibition after the induction of TNBS colitis. It would appear that the inhibitory effects exerted by the $\mathrm{PAR}_{1}$ antagonist may be caused by a direct effect on LPMCs, according to the data obtained by the in vitro studies of monocytic cell culture. Lamina propria cells isolated from TNBS-treated mice that were exposed to a $\mathrm{PAR}_{1}$ antagonist were refractory to stimulation with anti-CD3 and anti-CD28 antibodies. While the levels of IFN- $\gamma$ and TNF- $\alpha$ released by LPMCs from TNBS-treated mice with colitis were significantly increased compared with those released by cells from normal mice after anti-CD3/anti-CD28 stimulation, $\mathrm{PAR}_{1}$ antagonist treatment of these mice completely abolished this inflammation-induced increase in cytokine production. $\mathrm{PAR}_{1}$ is known to be expressed in monocytic cells and lymphocytes (30-32), and a growing body of evidence suggests that $\mathrm{PAR}_{1}$ can modulate immune cell functions. The fact that $\mathrm{PAR}_{1}$ agonist-induced inflammation is completely absent at 7 days in SCID and RAG1/- mice strongly suggests a role for acquired immunity in general, and $\mathrm{B}$ and/or $\mathrm{T}$ lymphocytes in particular, in the ability of $\mathrm{PAR}_{1}$ activation to cause chronic inflammation of the bowel. Innate immunity through the activation of monocytes and monocyte-derived macrophages might also be implicated, since $\mathrm{PAR}_{1}$ agonists can cause cell activation and cytokine release in those cells $(32,33)$. Moreover, we have shown here (Figure $8 \mathrm{C}$ ) that $\mathrm{PAR}_{1}$ agonists were able to induce IFN- $\gamma$ release from monocytic cells isolated from mouse intestinal lamina propria, thereby further supporting the idea that $\mathrm{PAR}_{1}$ activation on those cells is responsible, at least partly, for the inflammatory response. In the intestine, inhibition of $\mathrm{PAR}_{1}$ activation in $\mathrm{PAR}_{1}$-expressing monocytes and/or lymphocytes after $\mathrm{PAR}_{1}$ 
antagonist treatment might be responsible for the inhibition of TNBS-induced colitis development. Taken together, these results suggest that $\mathrm{PAR}_{1}$ activation on monocytic cells and the subsequent release of inflammatory cytokines are responsible, at least in part, for the pathogenesis of TNBS-induced colitis.

Although our results clearly demonstrate a proinflammatory role for $\mathrm{PAR}_{1}$ activation in the colon, other studies have reported a protective role for $\mathrm{PAR}_{1}$ activation in rat gastric mucosa (34). In their study, Kawabata et al. suggested a protective effect in the rat gastric mucosa due to prostaglandin release. This is in accord with the protective effects of prostaglandins in stomach. However, in other tissues, such as the colon of IBD patients, the large presence of prostaglandin $\mathrm{E}_{2}$ is due to the activation of inflammatory cascade and is associated with the severity of inflammation (35). Thus, if $\mathrm{PAR}_{1}$ activation induces prostaglandin release as suggested by the study of Kawabata et al. (34), in colonic tissues, we can hypothesize that such release participates in the inflammatory reaction developed by IBD patients.

Thrombin has been shown to activate $\mathrm{PAR}_{1}$ in vitro and is considered the endogenous activator of $\mathrm{PAR}_{1}$ on platelets (36). Other proteases from the coagulation cascade, such as factor Xa or VIIa, have also been shown to activate $\mathrm{PAR}_{1}$ (reviewed in ref. 37). If proteases from the coagulation cascade, such as thrombin, factor $\mathrm{Xa}$, or factor VIIa, are the endogenous activators of $\mathrm{PAR}_{1}$ in the colon of IBD patients, they might not act as primary factors in the development of inflammation but might prolong the inflammatory reaction after their release from injured tissue. Although no studies have reported the effects of intestinal bacteria (pathogens or nonpathogens) on PAR activation, studies have reported the possible activation of $\mathrm{PAR}_{1}$ by proteases from pathogens such as Porphyromonas gingivalis (5) or dust mites $(38,39)$. Therefore, in the context of IBD, we cannot rule out the possibility that bacterial proteases might be implicated in $\mathrm{PAR}_{1}$ activation and might participate in inflammation. This hypothesis is in accord with the role proposed for bacteria in the development of IBD (22).

In conclusion, our results show that $\mathrm{PAR}_{1}$ expression is upregulated in biopsies from IBD patients, that $\mathrm{PAR}_{1}$ activation in the colon of mice leads to an inflammatory reaction involving lymphocytes, and that $\mathrm{PAR}_{1}$ activation plays a role in the pathogenesis of an experimental model of IBD. These results support our hypothesis that $\mathrm{PAR}_{1}$ activation plays a proinflammatory role in IBD. This role involves, secondarily, an increase in intestinal permeability, and, primarily, the activation of monocytic cells from the lamina propria, leading to cytokine release. As $\mathrm{PAR}_{2}$ was shown to play a role in models of arthritis (40) and is therefore an interesting target for chronic inflammation, the present study highlights another of the PARs, $\mathrm{PAR}_{1}$, as a possible target for the treatment of IBD.

\section{Methods}

Human biopsies. Biopsies of human colon were collected from patients during colonoscopy procedures performed at the Foothills Hospital (Calgary, Alberta, Canada). Control tissues were gathered from patients (4 men, 1 woman) undergoing screening colonoscopies for colon cancer surveillance. Crohn disease patients (4 women, 1 man) and ulcerative colitis patients ( 4 men, 2 women) underwent colonoscopy for diagnosis or assessment of disease activity. Biopsies from patients with colitis were taken from endoscopically inflamed areas. Histological assessment was carried out on biopsies that were adjacent to the areas that were sampled for RNA assessment. The protocol for these studies was approved by the University of Calgary Ethics Review Committee.
Colon specimens from 5 patients were used for quantitative real-time RT-PCR analysis of $\mathrm{PAR}_{1}$ expression. Patients ( 3 males, mean age $37.4 \pm 5.6$ ) presented a colon localization of Crohn disease in all cases. Two patients also presented intestinal involvement. Diagnosis was made 2-5 years earlier by endoscopy, $\mathrm{x}$-ray examination, and colon biopsies. All patients presented a disease flare at the moment of the examination (mean Crohn disease activity index was $352.0 \pm 43.5$ ). All patients were taking 5-aminosalycilic acid, and biopsies were harvested before corticosteroid therapy began. Biopsies were taken during colonoscopy from either macroscopically normal or diseased colon. A mean of 6-8 biopsies for each localization were taken and immediately processed for RNA extraction.

Animals. C57BL/6 and BALB/c mice were obtained from Charles River Laboratories Inc., and C57BL/6J SCID mice, B6 mice, 129S-RAG1 $/-$ mice, and congenic controls were purchased from The Jackson Laboratory. C57BL/6 mice were used for all the experiments except those performed with the $\mathrm{PAR}_{1}$ antagonist, for which $\mathrm{BALB} / \mathrm{c}$ mice were used. $\mathrm{PAR}_{1}^{-/-}$mice and littermates (C57BL/6 background) were originally provided by Johnson \& Johnson Pharmaceutical Research and Development and bred at the University of Calgary. All mice were housed in a temperature-controlled room and had free access to food and water. The Animal Care Committee of the University of Calgary and the Animal Care Committee of the University of Perugia approved all experimental protocols.

Chemicals. Peptides (the selective $\mathrm{PAR}_{1}$-activating peptide TFLLR- $\mathrm{NH}_{2}$ and the control peptide RLLFT- $\mathrm{NH}_{2}$, which is inactive on $\mathrm{PAR}_{1}$ ) were obtained from the Peptide Synthesis Facility of the Faculty of Medicine of the University of Calgary. The $\mathrm{PAR}_{1}$ antagonist used is a derivative of RWJ56110, a known $\mathrm{PAR}_{1}$ antagonist, in which the ethylamino group and the difluorobenzyl group have been substituted with paramethoxybenzenzyl and arginine, respectively. The chemical structure of the $\mathrm{PAR}_{1}$ antagonist used in the present study, L-arininamide-4-methoxy- $N$-[[[1-[92,6-dichlorophenyl-methyl]-3-(1-pyrrolidinylmethyl)- $1 H$-indol-6-yl]amino]carbonyl]l-phenylalanyl- $N$-(phenylmethyl)-(5). This compound has been shown to inhibit $\mathrm{PAR}_{1}$-mediated platelet activation $(41,42)$ with an $\mathrm{IC}_{50}$ of $0.6 \mu \mathrm{M}$. The $\mathrm{PAR}_{1}$ antagonist was synthesized by G. Caliendo and V. Santagada in the Department of Medicinal Chemistry at the University of Naples. The NK-1 antagonist SR140333 was a gift from X. Edmonds-Alt (Sanofi Recherches, Montpellier, France), and capsaicin was purchased from Sigma-Aldrich. TNBS was purchased from Sigma-Aldrich.

RT-PCR. For human tissues, 2 colonic biopsies per patient were removed, rinsed, and immediately placed in RNAlater (Ambion Inc.) and frozen at $-20^{\circ} \mathrm{C}$. Samples were then transferred to $1 \mathrm{ml}$ of TRIzol for further processing. RNA was isolated using TRIzol reagent (Invitrogen Corp.) according to the instructions of the manufacturer.

The PCR reaction was performed using $2 \mu \mathrm{l}$ of cDNA. This product was amplified in a final concentration of 1 PCR buffer (PerkinElmer/Cetus), $0.8 \mu \mathrm{M}$ of each primer, $0.2 \mathrm{mM}$ of dNTPs, and $1 \mathrm{U}$ of Taq polymerase (PerkinElmer/Cetus) in a total volume of $50 \mu \mathrm{l}$. Semiquantitative PCR used the "primer-dropping" method, in which GAPDH was coamplified as an internal control in all reactions as described. Aliquots of PCR reactions (approximately $20 \mu \mathrm{l}$ ) were equalized to the equivalent signals from the GAPDH mRNA and separated by electrophoresis through $1 \%$ agarose gels containing $0.2 \mu \mathrm{g} / \mathrm{ml}$ ethidium bromide. Gels were photographed and analyzed by densitometry using NIH imaging software. $\mathrm{PAR}_{1}$ mRNA expression is presented as a ratio to GAPDH. The primer sequences for $\mathrm{PAR}_{1}$ were $5^{\prime}$ TGTGAACTGATCATGTTTATG-3', sense, and 5'-TTCGTAAGATAAGAGATATGT- $3^{\prime}$, antisense, and the cycling parameters were 30 seconds at $94^{\circ} \mathrm{C}$, 30 seconds at $55^{\circ} \mathrm{C}$, and 30 seconds at $72^{\circ} \mathrm{C}$ for 31 cycles, with a product size of $708 \mathrm{bp}$. The primer sequences for GAPDH were $5^{\prime}$-CGGAGTCAACCGGATTTGGTCGTAT-3', sense, and 5'-AGCCTTCTCCATGGTGGTGAAGAC- $3^{\prime}$, antisense, added for 21 cycles, with a product size of $307 \mathrm{bp}$. 
For RT-PCR performed in mouse tissues, total RNA was isolated using TRIzol reagent (Invitrogen Corp.) as previously described (43). The sense and antisense primers, respectively, were as follows: $\beta$-actin (540 bp), $5^{\prime}$ TGTGATGGTGGGAATGGGTCAG- $3^{\prime}$ and $5^{\prime}$-TTTGATGTCACGCACGATTTCC-3' (Stratagene); IFN- $\gamma$ (405 bp), 5'-TACTGCCAGGGCACAGTCATTGAA-3' and 5'-GCAGCGACTCCTTTTCCGCTTCCT-3' (Stratagene); TNF- $\alpha$ (276 bp), 5'-ATGAGCACAGAAAGCATGATC-3' and 5'-TACAGGCTTGTCACTCGAATT-3' (Stratagene); IL-2 (451 bp), 5'-GTCAACAGCGCACCCACTTCAAGC-3' and 5'-GCTTGTTGAGATGATGCTTTGACA-3' (Stratagene); COX-1 (391 bp), 5'-TTTTTTTTCATGTAACATCTTC-3' and 5'-TTAAAACTGAACTTGGACCC-3' (Sigma-Aldrich); COX-2 (420 bp), 5'CATGGGTGTGAAGGGAAATAAG-3' and $5^{\prime}$-GGCATACATCATCAGACCAG-3' (Sigma-Aldrich); constitutive NO synthase (190 bp), 5'-GAGTACCGCTGCAGAGGGGG-3' and $5^{\prime}$-GCTCGCCGCTTCGTGGGGG-3' (Sigma-Aldrich); iNOS (231 bp), 5'-CTTCAACACCAAGGTTGTCTGCAT$3^{\prime}$ and 5'-ATGTCATGAGCAAAGGCGCAGAAC-3' (Maxim Biotech Inc.). The cDNA was amplified with a "hot start" reaction $(20 \mu \mathrm{l})$ containing $5 \mu \mathrm{l}$ cDNA product, $2 \mu \mathrm{l}$ PCR buffer $(200 \mathrm{mM}$ Tris-HCl, $\mathrm{pH}$ 8.4, $500 \mathrm{mM}$ $\mathrm{KCl}), 200 \mu \mathrm{M}$ dNTPs, $1 \mu \mathrm{M}$ of each of the sense and antisense primers, 1.5 $\mathrm{mM} \mathrm{MgCl} 2,1 \mathrm{U}$ Platinum Taq polymerase (Invitrogen Corp.), and water in a Hybaid PCR Sprint thermocycler (Celbio). PCR was carried out for 35 cycles ( 30 for amplification of $\beta$-actin) as follows: $94^{\circ} \mathrm{C}$ for 30 seconds, $60^{\circ} \mathrm{C}$ for 15 seconds, and $72^{\circ} \mathrm{C}$ for 30 seconds, with a final extension at $72^{\circ} \mathrm{C}$ for 5 minutes. PCR products were separated on a $1.5 \%$ agarose gel, and band intensity was quantified using Kodak Digital Science ID Image Analysis software (Eastman Kodak Co.). Each assay was carried out in triplicate. The $\beta$-actin primers were used as a control for both reverse transcription and the PCR reaction itself.

Quantitative real-time RT-PCR. For quantitative PCR analysis, PCR primers were designed using Primer3 software (http://fokker.wi.mit.edu/cgibin/primer3/primer3_www.cgi) and the Primer Express program (Applied Biosystems), using published sequence data from the National Center for Biotechnology Information database (http://www.ncbi.nlm.nih.gov). Total RNA was isolated from colon biopsies using TRIzol reagent (Invitrogen Corp.). One microgram RNA was purified of the genomic DNA by DNase I treatment (Invitrogen Corp.) for 15 minutes at room temperature. The DNase I was inactivated at $95^{\circ} \mathrm{C}$ for 5 minutes in the presence of $2.5 \mathrm{mM}$ EDTA. The RNA was random-reverse-transcribed with SuperScript III (Invitrogen Corp.) in a 20- $\mu \mathrm{l}$ reaction volume. One hundred nanograms of template was used in a real-time PCR reaction with a final volume of $25 \mu \mathrm{l}$, containing $0.3 \mu \mathrm{M}$ of each primer and $12.5 \mu \mathrm{l}$ of 2 SYBR Green PCR Master Mix (Bio-Rad Laboratories). All reactions were performed in triplicate, and the thermal cycling conditions were 2 minutes at $95^{\circ} \mathrm{C}$, followed by 50 cycles of $95^{\circ} \mathrm{C}$ for 10 seconds and $60^{\circ} \mathrm{C}$ for 30 seconds in an iCycler iQ instrument (Bio-Rad Laboratories). The mean value of the replicates for each sample was calculated and expressed as cycle threshold $\left(C_{\mathrm{T}}\right.$; the cycle number at which each PCR reaction reaches a predetermined fluorescence threshold, set within the linear range of all reactions). The amount of gene expression was then calculated as the difference $\left(\Delta C_{T}\right)$ between the $C_{T}$ value of the sample for the target gene and the mean $C_{\mathrm{T}}$ value of that sample for the endogenous control. Relative expression was calculated as the difference $\left(\Delta \Delta C_{\mathrm{T}}\right)$ between the $\Delta C_{\mathrm{T}}$ values of the test sample and of the control sample (WT) for each target gene. The relative quantification value was expressed and shown as $2^{-\Delta \Delta C_{\mathrm{T}}}$.

Immunohistochemistry. For the human biopsies, colon specimens were obtained from a 43-year-old male patient undergoing colon-ileal resection for Crohn disease. Samples, obtained from an injured area and from a macroscopically normal colon immediately close to the rim of resection, were fixed in Zamboni's fixative for 24 hours at room temperature, and embedded in paraffin. Tissue sections were incubated with a goat anti- human polyclonal antibody (Santa Cruz Biotechnology Inc.) at a dilution of 1:200 to 1:1,000. The sections were washed 3 times in PBS and incubated with peroxidase-conjugated rabbit anti-goat IgG (Santa Cruz Biotechnology Inc.) at a dilution of 1:200 for 2 hours at room temperature. Tissue sections were washed 3 times in PBS, postfixed with $4 \%$ paraformaldehyde, washed again, and mounted (ProLong; Invitrogen Corp.). The immunolocalization of $\mathrm{PAR}_{1}$ was observed and photographed by light microscopy (Olympus Optical Co.). In blocking experiments, the diluted primary antibody $(1: 1,000)$ was preincubated for 24 hours at $4^{\circ} \mathrm{C}$ with $20 \mu \mathrm{g} / \mathrm{ml}$ of blocking peptide (Santa Cruz Biotechnology Inc.).

In mice, tissues were harvested, fixed in $10 \%$ formalin for 48 hours, and embedded in paraffin. Sections of $5 \mu \mathrm{m}$ were cut, deparaffinized, and boiled in $0.01 \mathrm{M}$ citrate buffer, $\mathrm{pH}$ 6.0, for 10 minutes. Incubation in $0.3 \%$ hydrogen peroxide to inhibit endogenous peroxidase activity was followed by washes and incubation with the primary anti-PAR ${ }_{1}$ antibody (Thrombin R [C18]; Santa Cruz Biotechnology Inc.) at a concentration of 1:100 in 10\% normal serum. After 3 series of washes in PBS, sections were incubated with a secondary peroxidase-conjugated antibody (Jackson ImmunoResearch Laboratories Inc.) at a dilution of 1:500 for 1 hour at room temperature. Peroxidase activity in tissue sections was revealed using DAB substrate kit (Vector Laboratories Inc.).

Colitis induction and study design. Mice fasted for 12 hours were lightly anesthetized with halothane, and a polyethylene catheter was inserted intrarectally $4 \mathrm{~cm}$ from the anus. All compounds given intracolonically were administered through the catheter at a maximum volume of $100 \mu \mathrm{l}$, as previously described (44).

Peptides (TFLLR- $\mathrm{NH}_{2}$ and RLLFT- $\mathrm{NH}_{2}$ ) were dissolved in $10 \%$ ethanol, $10 \%$ Tween-80, and $80 \%$ saline $(0.9 \% \mathrm{NaCl})$. At different times after the intracolonic administration of the peptides or their vehicle, mice ( 8 in each group) were sacrificed and distal colonic tissues were harvested. For all studies except the study with the $\mathrm{PAR}_{1}$ antagonist, macroscopic-damage score was assessed as previously described (44), scoring inflammatory parameters such as erythema, hemorrhage, edema, stricture formation, ulceration, presence of blood in the feces, mucus presence, diarrhea, and adhesions. MPO activity was assessed as an index of granulocyte infiltration (44). Other tissues adjacent to the site of inflammation were fixed in neutral-buffered formalin and processed by routine histology techniques for microscopic observation (44). Capsaicin $(50 \mathrm{mg} / \mathrm{kg} \mathrm{s.c.)} \mathrm{or} \mathrm{its} \mathrm{vehicle}$ (80\% saline, $10 \%$ ethanol, $10 \%$ Tween- 80 ) was administered 7 days before the intracolonic administration of $\mathrm{PAR}_{1}$-activating peptide, and the efficacy of capsaicin pretreatment in ablating sensory nerves was tested just before the sacrifice of the mice, as previously described $(25,45)$. The NK-1 receptor antagonist SR140333 was administered i.p. $(2 \mathrm{mg} / \mathrm{kg}$ in $0.1 \%$ DMSO) 1 hour before the intracolonic injection of the $\mathrm{PAR}_{1}$-activating peptide (25). This dose has previously been shown to fully inhibit NK-1 receptor activation (46).

TNBS $(0.5,1$, and $2 \mathrm{mg} /$ mouse) was dissolved in a solution of saline $(0.9 \% \mathrm{NaCl})$ plus ethanol and was injected into the colon of mice to induce colitis. As previously described (47), ethanol was used as a "breaker" of the intestinal barrier, which allows TNBS to penetrate colonic tissues. Different concentrations of ethanol lead to different degrees of TNBS penetration into the tissues, resulting in different degrees of inflammation. Therefore, we used 2 different concentrations of ethanol ( $40 \%$ or $50 \%$ ), associated with different concentrations of TNBS, in order to evaluate various inflammatory states. For the experiments aiming to determine whether $\mathrm{PAR}_{1}$ activation exacerbates colitis, the $\mathrm{PAR}_{1}$-activating peptide TFLLR- $\mathrm{NH}_{2}$ or the control peptide RLLFT- $\mathrm{NH}_{2}$ (each at the dose of $50 \mu \mathrm{g} /$ mouse) was administrated intracolonically or intraperitoneally, 1 hour before and daily after TNBS administration ( $1 \mathrm{mg} / \mathrm{mouse}$ of TNBS in $40 \%$ ethanol). Low concentrations of ethanol (40\%) and TNBS (1 mg/mouse) were chosen for this experiment 
because of the potential aggravating effects of $\mathrm{PAR}_{1}$ agonist treatment, in order to reduce potential lethality. Each group consisted of 10 mice. Body weight was recorded daily as an index of disease progression, and the same inflammatory parameters (macroscopic-damage score, MPO) were assessed 7 days after TNBS administration, when mice were sacrificed. For the studies performed with the $\mathrm{PAR}_{1}$ antagonist, $\mathrm{BALB} / \mathrm{c}$ mice received an intrarectal administration of TNBS on day 1 ( 1 or $2 \mathrm{mg} / \mathrm{mouse}$ in $50 \%$ ethanol), and then different doses of the $\mathrm{PAR}_{1}$ antagonist $(1,3$, and $5 \mathrm{mg} / \mathrm{kg}$ ) or its vehicle (carboxymethyl cellulose) were administered i.p. each day, from day 1 (3 hours after TNBS administration) to day 7 , as previously described (42). Here again, 2 concentrations of TNBS were used to evaluate the effects of the $\mathrm{PAR}_{1}$ antagonist on different inflammatory states. Each group consisted of 12 mice. Survival rate (for the $2-\mathrm{mg} /$ mouse dose of TNBS only) and body weight were recorded. Seven days after TNBS administration, mice were sacrificed and distal colonic tissues were harvested. Macroscopic- and microscopic-damage scores were assessed, blindly, using a dissecting microscope (5) and graded for macroscopic lesions on a scale from 0 to 10 based on criteria reflecting inflammation, such as hyperemia, thickening of the bowel, and the extent of ulceration $(43,48)$.

For histological examination, a specimen of colon located precisely 2 $\mathrm{cm}$ proximal to the anus was resected, fixed in $10 \%$ phosphate-buffered formalin, embedded in paraffin, sectioned, and stained with H\&E. Slides were examined and graded in a blinded fashion. Inflammation was graded semiquantitatively from 0 to 4 ( 0 : no signs of inflammation; 1 : very low level of inflammation; 2: low level of leukocyte infiltration; 3 : high level of leukocyte infiltration, high vascular density, thickening of the colon wall; 4: transmural infiltrations, loss of goblet cells, high vascular density, thickening of the colon wall).

Colonic tissue samples were also used to measure TNF- $\alpha$ and IFN- $\gamma$ protein content by ELISA. For the studies performed with $\mathrm{PAR}_{1}{ }^{-/-}$mice and their littermates, different doses of TNBS (0.5, 1 , and $2 \mathrm{mg}$ /mouse) were used with different concentrations of ethanol ( $40 \%$ and $50 \%$ ), in order to evaluate different degrees of inflammatory responses. Survival rate was followed for the highest concentration of TNBS and ethanol ( $2 \mathrm{mg} /$ mouse in $50 \%$ ethanol); body weight, macroscopic-damage score, MPO activity, and histological examination were followed for all TNBS and ethanol conditions.

As described previously by Okayasu et al. (49), DSS colitis was induced in $\mathrm{BALB} / \mathrm{c}$ mice that, for 7 days, received 5\% (wt/vol) DSS (molecular weight, $40 \mathrm{kDa}$; ICN Biomedicals Inc.) dissolved in their drinking water, which was filtered using water purification systems from Millipore Corp. No mortality was observed during the 7 days of DSS administration in all groups.

Development of colitis was assessed daily by measurement of drinking volume and body weight, evaluation of stool consistency, and detection of the presence of blood in the stools using a guaiac paper test (Eiken Chemical Co.). Disease severity was scored as described previously by Cooper et al. (50), using a clinical disease activity index ranging from 0 to 4 that was calculated using the following parameters: stool consistency, presence or absence of fecal blood, and weight loss. Mice were sacrificed at day 8 for the $\mathrm{PAR}_{1}$ antagonist experiments and day 7 for the $\mathrm{PAR}_{1}{ }^{-/-}$mouse experiments. The colons were removed; length and weight were measured after exclusion of the cecum and prior to division for histology and RNA extraction. Histology was scored and MPO was measured as described for the TNBS model.
Isolation of LPMCs. LPMCs were isolated from freshly obtained mouse colonic specimens using a modification of a previously described technique (51). In brief, after excision of all visible lymphoid follicles, colons were washed in calcium- and magnesium-free HBSS and treated with 1 mM EDTA in PBS for 20 minutes to remove the epithelium. The tissue was then digested with type IV collagenase (Sigma-Aldrich) for 20 minutes in a shaking incubator at $37^{\circ} \mathrm{C}$; this step was repeated twice. The released cells were then layered on a $40-100 \%$ Percoll gradient (Amersham Pharmacia Biotech Inc.) and centrifuged at $500 \mathrm{~g}$ to obtain the lymphocyte-enriched populations at the $40-100 \%$ interface (43).

Culture of LPMCs for assay of cytokine production. LPMCs from the different treatment regimens were suspended in complete medium (RPMI $1640,10 \%$ heat-inactivated FCS, $3 \mathrm{mM} \mathrm{l-glutamine,} 10 \mathrm{mM}$ HEPES buffer, $10 \mu \mathrm{g} / \mathrm{ml}$ gentamycin, $100 \mathrm{U} / \mathrm{ml}$ penicillin, $100 \mathrm{U} / \mathrm{ml}$ streptomycin, $0.05 \mathrm{mM} 2$ - $\beta$-Mercapto-Ethanol) and cultured at a concentration of $10^{6}$ cells per milliliter. To measure cytokine production, $10^{6} \mathrm{LPMCs}$ were placed for 48 hours into uncoated culture wells (to measure production by unstimulated cells) or into wells containing immobilized murine anti-CD3 $\varepsilon$ antibody (clone 145-2C11; Pharmingen) and $1 \mu \mathrm{g} / \mathrm{ml}$ soluble anti-CD28 (clone 37.51; Pharmingen) (to measure production by stimulated cells) (44). Culture supernatants were harvested and assayed for cytokine concentration by ELISA (Endogen Inc.). Some cells were incubated for 24 hours in the presence of $10 \mu \mathrm{M}$ of the PAR $_{1}$ agonist TFLLR or the control peptide RLLFT (which is inactive on $\mathrm{PAR}_{1}$ ), with or without anti-CD3/anti-CD28 stimulation.

Data analysis. Comparisons among groups were made using 2-tailed Student's $t$ tests with Bonferroni correction. Data are expressed as mean \pm SEM, and a $P$ value less than 0.05 was considered significant.

\section{Acknowledgments}

We want to thank Giuseppe Caliendo and Vincenzo Santagada, who have synthesized the $\mathrm{PAR}_{1}$ antagonist. This study was supported by operating grants from the Canadian Institutes of Health Research (CIHR) (to N. Vergnolle, P. Beck, M.D. Hollenberg, and J.L. Wallace), by a Proteases and Inflammation Network group grant from the CIHR (to N. Vergnolle, P. Beck, M.D. Hollenberg, and J.L. Wallace), by the Canadian Association of Gastroenterology (to N. Vergnolle), by the Crohn's and Colitis Foundation of Canada (to N. Vergnolle, P. Beck, and J.L. Wallace), and by a Johnson \& Johnson Focused Giving Grant (to J.L. Wallace, M.D. Hollenberg, and N.W. Bunnett).

Received for publication March 23, 2004, and accepted in revised form September 14, 2004.

Address correspondence to: Nathalie Vergnolle, Department of Pharmacology and Therapeutics, University of Calgary, 3330 Hospital Drive NW, Calgary, Alberta T2N4N1, Canada. Phone: (403) 220-4588; Fax: (403) 210-8195; E-mail: nvergnol@ucalgary.ca.

Nathalie Vergnolle and Stefano Fiorucci contributed equally to this work.
1. Hollenberg, M.D., and Compton, S.J. 2002. International Union of Pharmacology. XXVIII. Proteinaseactivated receptors. Pharmacol. Rev. 54:203-217.

2. Macfarlane, S.R., Seatter, M.J., Kanke, T., Hunter, G.D., and Plevin, R. 2001. Proteinase-activated receptors. Pharmacol. Rev. 53:245-282.

3. Hollenberg, M.D., Saifeddine, M., Al-Ani, B., and Kawabata, A. 1997. Proteinase-activated receptors: structural requirements for activity, receptor cross- reactivity, and receptor selectivity of receptor-activating peptides. Can. J. Physiol. Pharmacol. 75:832-841.

4. Vergnolle, N., Wallace, J.L., Bunnett, N.W., and Hollenberg, M.D. 2001. Protease-activated receptors in inflammation, neuronal signaling and pain. Trends Pharmacol. Sci. 22:146-152.

5. Lourbakos, A., et al. 2001. Arginine-specific protease from Porphyromonas gingivalis activates protease-activated receptors on human oral epithe- lial cells and induces interleukin-6 secretion. Infect. Immun. 69:5121-5130.

6. Vu, T., Hung, D., Wheaton, V., and Coughlin, S. 1991. Molecular cloning of a functional thrombin receptor reveals a novel proteolytic mechanism of receptor activation. Cell. 64:1057-1068.

7. Coughlin, S.R., and Camerer, E. 2003. PARticipation in inflammation. J. Clin. Invest. 111:25-27. doi:10.1172/JCI200317564. 
8. Asokananthan, N., et al. 2002. Activation of protease-activated receptor (PAR)-1, PAR-2, and PAR-4 stimulates IL-6, IL-8, and prostaglandin E2 release from human respiratory epithelial cells. J. Immunol. 168:3577-3585.

9. Boven, L.A., et al. 2003. Up-regulation of proteinaseactivated receptor 1 expression in astrocytes during HIV encephalitis. J. Immunol. 170:2638-2646.

10. Cirino, G., et al. 1996. Thrombin functions as an inflammatory mediator through activation of its receptor. J. Exp. Med. 183:821-827.

11. Copple, B.L., Moulin, F., Hanumegowda, U.M., Ganey, P.E., and Roth, R.A. 2003. Thrombin and protease-activated receptor-1 agonists promote lipopolysaccharide-induced hepatocellular injury in perfused livers. J. Pharmacol. Exp. Ther. 305:417-425.

12. Vergnolle, N., Hollenberg, M.D., and Wallace, J.L. 1999. Pro- and anti-inflammatory actions of thrombin: a distinct role for proteinase-activated receptor-1 (PAR1). Br. J. Pharmacol. 126:1262-1268.

13. Corvera, C.U., et al. 1999. Thrombin and mast cell tryptase regulate guinea-pig myenteric neurons through proteinase-activated receptors- 1 and -2 . J. Physiol. 517:741-756.

14. Dery, O., Corvera, C., Steinhoff, M., and Bunnett, N. 1998. Proteinase-activated receptors: novel mechanisms of signaling by serine proteases. Am. J. Physiol. 274:C1429-C1452.

15. Vergnolle, N. 2000. Review article. Proteinaseactivated receptors: novel signals for gastrointestinal pathophysiology. Aliment. Pharmacol. Ther. 14:257-266.

16. Buresi, M.C., et al. 2001. Protease-activated receptor-1 stimulates $\mathrm{Ca}(2+)$-dependent $\mathrm{Cl}(-)$ secretion in human intestinal epithelial cells. Am. J. Physiol. Gastrointest. Liver Physiol. 281:G323-G332.

17. Chin, A.C., et al. 2003. Proteinase-activated receptor- 1 induces apoptosis and increases intestinal permeability. Proc. Natl. Acad. Sci. U. S. A. 100:11104-11109.

18. Darmoul, D., Gratio, V., Devaud, H., Lehy, T. and Laburthe, M. 2003. Aberrant expression and activation of the thrombin receptor protease-activated receptor- 1 induces cell proliferation and motility in human colon cancer cells. Am. J. Pathol. 162:1503-1513.

19. Seymour, M.L., Zaidi, N.F., Hollenberg, M.D., and Macnaughton, W.K. 2003. PAR1-dependent and independent increases in COX-2 and PGE2 in human colonic myofibroblasts stimulated by thrombin. Am. J. Physiol. Cell Physiol. 284:C1185-C1192.

20. Mule, F., Baffi, M.C., and Cerra, M.C. 2002. Dual effect mediated by protease-activated receptors on the mechanical activity of rat colon. Br. J. Pharmacol. 136:367-374

21. Mule, F., Baffi, M.C., Falzone, M., and Cerra, M.C. 2002. Signal transduction pathways involved in the mechanical responses to protease-activated receptors in rat colon. J. Pharmacol. Exp. Ther. 303:1265-1272.

22. Kirsner, J.B. 2000. Inflammatory bowel disease. 5th edition. W.B. Saunders Co. Philadelphia, Pennsylvania, USA. $832 \mathrm{pp}$

23. Bustos, D., et al. 1998. Colonic proteinases: increased activity in patients with ulcerative colitis. Medicina (B. Aires). 58:262-264.

24. Kjeldsen, J., Lassen, J., Brandslund, I., and Schaffalitzky de Muckadell, O. 1998. Markers of coagulation and fibrinolysis as measures of disease activity in inflammatory bowel disease. Scand. J. Gastroen terol. 33:637-643.

25. Nguyen, C., et al. 2003. Proteinase-activated receptor-2-induced colitis is mediated by a neurogenic mechanism. Can. J. Physiol. Pharmacol. 81:920-927.

26. Elson, C.O., et al. 1996. Hapten-induced model of murine inflammatory bowel disease: mucosa immune responses and protection by tolerance. J. Immunol. 157:2174-2185.

27. de Garavilla, L., et al. 2001. Agonists of proteinaseactivated receptor 1 induce plasma extravasation by a neurogenic mechanism. Br. J. Pharmacol. 133:975-987.

28. Strater, J., et al. 1997. CD95 (APO-1/Fas)-mediated apoptosis in colon epithelial cells: a possible role in ulcerative colitis. Gastroenterology. 113:160-167.

29. McCafferty, D.M., Smith, C.W., Granger, D.N., and Kubes, P. 1999. Intestinal inflammation in adhesion molecule-deficient mice: an assessment of $\mathrm{P}$-selectin alone and in combination with ICAM-1 or E-selectin. J. Leukoc. Biol. 66:67-74.

30. Naldini, A., Sower, L., Bocci, V., Meyers, B., and Carney, D.H. 1998. Thrombin receptor expression and responsiveness of human monocytic cells to thrombin is linked to interferon-induced cellular differentiation. J. Cell. Physiol. 177:76-84.

31. Colognato, R., et al. 2003. Differential expression and regulation of protease-activated receptors in human peripheral monocytes and monocyte-derived antigen-presenting cells. Blood. 102:2645-2652.

32. Bar-Shavit, R., et al. 2002. Signalling pathways induced by protease-activated receptors and integrins in T cells. Immunology. 105:35-46.

33. Suk, K., and Cha, S. 1999. Thrombin-induced interleukin-8 production and its regulation by interferon-gamma and prostaglandin E2 in human monocytic U937 cells. Immunol. Lett. 67:223-227.

34. Kawabata, A., et al. 2004. A protective role of protease-activated receptor 1 in rat gastric mucosa. Gastroenterology. 126:208-219.

35. Hawkey, C.J., Karmeli, F., and Rachmilewitz, D. 1983. Imbalance of prostacyclin and thromboxane synthesis in Crohn's disease. Gut. 24:881-885.

36. Coughlin, S.R. 1999. How the protease thrombin talks to cells. Proc. Natl. Acad. Sci. U. S. A. 96:11023-11027.

37. Vergnolle, N. 2004. Modulation of visceral pain and inflammation by protease-activated receptors.
Br. J. Pharmacol. 141:1264-1274.

38. Sun, G., Stacey, M.A., Schmidt, M., Mori, L., and Mattoli, S. 2001. Interaction of mite allergens Der $\mathrm{p} 3$ and Der $\mathrm{p} 9$ with protease-activated receptor-2 expressed by lung epithelial cells. J. Immunol. 167:1014-1021.

39. Asokananthan, N., et al. 2002. House dust mite allergens induce proinflammatory cytokines from respiratory epithelial cells: the cysteine protease allergen, Der p 1, activates protease-activated receptor (PAR)-2 and inactivates PAR-1.J. Immunol. 169:4572-4578.

40. Ferrell, W.R., et al. 2003. Essential role for proteinase-activated receptor- 2 in arthritis. J. Clin. Invest. 111:35-41. doi:10.1172/JCI200316913.

41. Zhang, H.C., et al. 2001. Discovery and optimization of a novel series of thrombin receptor (par-1) antagonists: potent, selective peptide mimetics based on indole and indazole templates. J. Med. Chem. 44:1021-1024.

42. Fiorucci, S., et al. 2004. PAR1 antagonism protects against experimental liver fibrosis. Role of proteinase receptors in stellate cell activation. Hepatology. 39:365-375.

43. Fiorucci, S., et al. 2002. Importance of innate immunity and collagen binding integrin alpha1beta 1 in TNBS-induced colitis. Immunity. 17:769-780.

44. Cenac, N., et al. 2002. Induction of intestinal inflammation in mouse by activation of proteinaseactivated receptor-2. Am. J. Pathol. 161:1903-1915.

45. Steinhoff, M., et al. 2000. Agonists of proteinaseactivated receptor 2 induce inflammation by a neurogenic mechanism. Nat. Med. 6:151-158.

46. Amann, R., Schuligoi, R., Holzer, P., and Donnerer, J. 1995. The non-peptide NK1 receptor antagonist SR140333 produces long-lasting inhibition of neurogenic inflammation, but does not influence acute chemo- or thermonociception in rats. Naunyn Schmiedebergs Arch. Pharmacol. 352:201-205.

47. Morris, G.P., et al. 1989. Hapten-induced model of chronic inflammation and ulceration in the rat colon. Gastroenterology. 96:795-803.

48. Fiorucci, S., et al. 2001. Proteinase-activated receptor 2 is an anti-inflammatory signal for colonic lamina propria lymphocytes in a mouse model of colitis. Proc. Natl. Acad. Sci. U. S. A. 98:13936-13941.

49. Okayasu, I., et al. 1990. A novel method in the induction of reliable experimental acute and chronic ulcerative colitis in mice. Gastroenterology. 98:694-702.

50. Cooper, H.S., Murthy, S.N., Shah, R.S., and Sedergran, D.J. 1993. Clinicopathologic study of dextran sulfate sodium experimental murine colitis. Lab. Invest. 69:238-249.

51. Van der Heijden, P.J., and Stok, W. 1987. Improved procedure for the isolation of functionally active lymphoid cells from the murine intestine. J. Immunol. Methods. 103:161-167. 